\title{
DEFINIENDO EL ESTILO ALTIPLÁNICO DE BOLSAS CHUSPAS A TRAVÉS DE LOS EJEMPLARES DEL CEMENTERIO PREHISPÁNICO DE AZAPA 15, ARICA, CHILE
}

\author{
DEFINING THE ALTIPLANO STYLE OF CHUSPA BAGS FROM SAMPLES \\ FOUND AT THE AZAPA- 15 PREHISPANIC CEMETERY IN ARICA, CHILE
}

Muriel Paulnyy Horta

Este artículo es el resultado de un estudio textil de las bolsas chuspas asociadas a los ajuares funerarios del cementerio prehispánico de Azapa 15, ubicado en el valle de Azapa, Arica, Chile. En la muestra se aprecia un conjunto de ejemplares exógenos que difiere formal y técnicamente de los estilos ya definidos por la investigación de los textiles prehispánicos del área. Para dicho conjunto se propone la denominación de estilo Altiplánico. Así, se aspira a establecer un nuevo indicador arqueológico que, junto con otros artefactos ya propuestos por la literatura especializada, sirva para dar luces acerca de la filiación étnica de la población asentada en este valle costero.

Palabras clave: textiles prehispánicos, bolsas chuspas, Período Tardío, mitimaes, Arica, cementerio Azapa 15.

The present article outlines a textile analysis of chuspa bags associated with grave goods found in the pre-Hispanic cemetery of Azapa 15 (Azapa Valley, Arica, Chile). The sample shows a set of exogenous specimens that differs formally and technically from the styles defined by previous research on pre-Hispanic textiles from the area. With this group, which we propose calling the Altiplano style, we hope to establish a new archaeological indicator that, combined with other artifacts already examined in the literature, will tel us about ethnic affiliations of the population that settled in this coastal valley.

Keywords: pre-Hispanic textiles, chuspa bags, Late Period, mitimaes, Arica, Azapa cemetery 15.

\section{ANTECEDENTES 1}

La práctica andina prehispánica denominada "control vertical de un máximo de pisos ecológicos" fue planteada por Murra $(1972,1975,1976)$ a comienzos de la década de los setenta. Después de analizar los documentos conocidos como Visita hecha a la provincia de Chucuito, escrito en 1567 por Garci Diez de San Miguel sobre el señorío lupaca, y la Visita de la provincia de León de Huánuco en 1562, elaborado por Iñigo Ortiz tras su estadía en Huánuco, Murra (1975) planteó que, desde tiempos preincaicos, los reinos altiplánicos poseían colonias permanentes en sitios distantes de sus asentamientos de origen o de centros nucleares de mayor población. Debido a que el establecimiento de colonias obedecía a la intención de complementar las economías locales con productos propios de otros nichos ecológicos, estas se ubicaban en latitudes diferentes a las de los asentamientos principales, conformando unas especies de islas o archipiélagos en relación con el núcleo. El autor señala que la naturaleza del vínculo entre aquel y sus respectivos archipiélagos era de reciprocidad y redistribución, compartiendo ambos una sola organización económica y social (Murra 1976: 143). La práctica en cuestión no implicaba un

\footnotetext{
A Muriel Paulinyi Horta, Instituto de Historia, Pontificia Universidad Católica de Valparaíso. Diego Portales 355, Viña del Mar, código postal 2520000, e-mail: paulinyi.m@gmail.com
}

Recibido: diciembre 2016. Aceptado: marzo 2017. 
dominio territorial continuo, por lo que en un mismo nicho ecológico podían cohabitar simultáneamente junto a la población local, en caso de haberla, diversos grupos étnicos dependientes de sus respectivos núcleos de origen (Schiappacasse et al. 1989).

Si bien algunos investigadores concuerdan en que el control vertical de un máximo de pisos ecológicos se remontaría a tiempos previos al Tawantinsuyu (Murra 1972, 1975; Llagostera 1976, Rostworowski 1988; Schiappacasse et al. 1989; Horta 2015), esta práctica fue aprovechada aparentemente por la administración incaica, la que pasó a controlar la producción de las distintas islas o archipiélagos que los señoríos sometidos al imperio poseían. Además, bajo el nombre de mitimae, la administración imperial comenzó a establecer nuevos archipiélagos en sitios bastante más alejados de sus respectivos centros, desarticulando así el vínculo que caracterizaba la relación entre colonias y núcleos (Llagostera 1976; Murra 1976). Por otra parte, de acuerdo a lo mencionado en diversas crónicas, el fundamento de los traslados poblacionales también parece haber cambiado: el mitimae ya no se remitía tan solo a la necesidad de carácter económico que caracterizó a las colonias preincaicas, sino que también buscaba afianzar el dominio incaico en sitios fronterizos conflictivos y en regiones recientemente integradas al imperio (Murra 1976, Rostworowski 1988). ${ }^{2}$ De esta manera, se observa que la práctica del traslado poblacional bajo el Imperio Incaico se vinculó tanto a las dimensiones económica, política y militar (Rostworowski 1988).

¿Qué otras informaciones revelan las crónicas acerca de los mitimaes? El análisis de las fuentes etnohistóricas permite plantear que los individuos trasladados pertenecían al estrato social de los hatun runa. Se trata de hombres y mujeres de las comunidades indígenas, cuya fuerza de trabajo estaba a disposición de las distintas labores que el Estado estableciera como necesarias para el funcionamiento de la maquinaria imperial, como la mita, el yanaconaje y los mitimaes. Sabemos además que, al igual que en el caso de los archipiélagos preincaicos, el traslado poblacional de los mitimaes tenía un carácter definitivo, a diferencia del caso de la mita, en que los mitayos regresaban a sus lugares de origen una vez finalizado el turno de trabajo. Por otro lado, Cieza de León (1996 [1553]) menciona la existencia de un trato deferente entre el Inca y los individuos trasladados, el que respondía probablemente a la necesidad de reforzar la fidelidad de los desarraigados con el Estado. ${ }^{3}$
No obstante, por ordenanza imperial estos individuos seguían viviendo de acuerdo a sus costumbres originarias y continuaban utilizando la vestimenta propia de sus etnias, distinguiéndose de la población local y conformando así un segmento social distinto:

\begin{abstract}
[El Inca mandaba que los mitimaes] se quedasen por moradores perpetuos de los pueblos en que los ponía, guardando los usos y modo de vivir de los naturales de ellos, salvo que se quedaban con el traje, divisas y señales de los de su nación y provincia; lo cual han conservado hasta el tiempo presente, en que por las cosas dichas conocemos en cada pueblo los que son naturales de él o mitimaes (Cobo 1956 [1653]: 223).
\end{abstract}

Según la información entregada por los cronistas, la cantidad de mitimaes movilizados por los incas bajo el Tawantinsuyu fue considerable, existiendo traslados poblacionales en cada una de las provincias que conformaban el imperio. La existencia de mitimaes de origen altiplánico residiendo en los valles occidentales durante el Período Tardío ha sido planteada por diversos autores después de detectar en distintos documentos históricos información relevante sobre la presencia de población caranga en Azapa y Codpa, caranga y pacaje en Arica y lupaca en Lluta (Hidalgo 1981, 1996, 1997, 2004; Hidalgo \& Focacci 1986; Durston \& Hidalgo 1997). Para Llagostera (1976), corresponderían a grupos altiplánicos incanizados. En el marco general de la discusión acerca del origen de la población foránea trasplantada por el Estado Inca a los valles occidentales, el objetivo de nuestro estudio es contribuir a la definición étnica de dicha población a partir del estudio del registro textil de Azapa 15.

En un primer momento, tanto desde el registro arqueológico cerámico (cerámica Inca Regional, Inca Imperial y Saxamar) como del arquitectónico (ushnu), se planteó esta filiación altiplánica incanizada para la aldea y cementerio de Azapa 15 (Dauelsberg 1959,; Focacci 1981, Piazza 1981, Santoro \& Muñoz 1981). Más tarde, otros elementos del registro material, específicamente textiles y metales, fueron sugeridos como nuevos indicadores de la mencionada filiación (Carmona 2010, Figueroa 2012). Actualmente, la población del sitio en cuestión ha sido definida como un enclave de mitimaes altiplánicos de origen caranga, debido a la presencia en sus ajuares funerarios de artefactos tales como el gorro en técnica de aduja, el aríbalo con decoración de aspas, el quero con puma tallado en el borde, entre otros (Horta 2011, 2013, 2015). Además de constatarse la asociación 
de objetos de origen altiplánico en el sitio, la ausencia de piezas de raigambre local fue un segundo factor que consideraron los autores citados para respaldar la hipótesis del origen altiplánico de la población de Azapa 15.

En este artículo presentaremos los resultados de un estudio textil realizado a partir de las bolsas chuspas del sitio en cuestión. Partiendo del supuesto de que nos encontramos frente a una colonia de población trasladada por los incas desde tierras altiplánicas y culturalmente incanizada, proponemos que debiese ser posible identificar en el corpus rasgos tecnológicos y/o decorativos de raigambre altiplánica. Como es sabido, la identificación de dichos rasgos en tejidos de tierras altas no es una tarea fácil, ya que las condiciones climáticas del altiplano no permiten la conservación del material orgánico. Los pocos ejemplares hasta ahora registrados se conservaron gracias a circunstancias excepcionales (cuevas selladas, abrigos rocosos y chullpas), y su escaso número no ha permitido aún la definición de la tradición textil altiplánica post-tiwanaku. Por el contrario, sí existen definiciones acerca de las características estilísticas de las bolsas chuspas incaicas (Pollard 1995-1996), ariqueñas (Ulloa 1981, Horta \& Agüero 1997, Cassman 2000), tarapaqueñas (Agüero 1998, 2000) y chiribayas (Clark 1993, Minkes 2005). Por ello, el cotejo de los ejemplares de los ajuares funerarios de Azapa 15 con los de los estilos ya conocidos ayudaría a identificar elementos que nos permitan definir con mayor precisión el estilo altiplánico de chuspas. Parece poco probable que la impronta de la tradición textil de tierras altas hubiese desaparecido durante las décadas del dominio incaico ejercido sobre los reinos altiplánicos post-tiwanaku, y que los mitimaes trasladados a Azapa confeccionasen sus prendas de vestir tradicionales bajo cánones estrictamente incaicos.

Nuestro planteamiento obtiene respaldo si mencionamos el hecho de que en tiempos prehispánicos los textiles fueron considerados elementos indicadores de etnicidad, tal como ha sido ampliamente sostenido desde las evidencias arqueológicas y de otras disciplinas, como la etnografía y la etnohistoria (Ulloa 1981; Hodder 1982; Oakland 1992; Meisch 1997; Agüero 1998, 2012; Sinclaire 1998, 2001; Cassman 2000; Decoster 2005, entre otros). Se ha llegado a afirmar que los textiles serían la materialidad más relevadora en cuanto a determinación de etnicidades prehispánicas (Oakland 1992). Además, se ha planteado que la definición de la pertenencia étnica se puede lograr a través del estudio de los patrones de- corativos y de las particularidades tecnológicas de cada textil. En efecto, estudios etnohistóricos y arqueológicos vinculados a textiles prehispánicos han revelado que, a pesar de estar en constante contacto con otras comunidades, los distintos grupos étnicos mantenían intactas sus propias tradiciones textiles a lo largo del tiempo, las que se transformaban en un sello de pertenencia étnica que los diferenciaba de manera inmediata de los miembros de otros grupos. ${ }^{4}$

Finalmente, consideramos que debiese ser posible detectar los rasgos y patrones tecnológicos arriba mencionados, debido a que existen otras prendas textiles asociadas a Azapa 15, tales como el gorro troncocónico en técnica de aduja, la faja en twill y los unkus listados, que no fueron confeccionadas sobre la base de opciones tecnológicas y decorativas locales, incaicas y tarapaqueñas, sino más bien, según la catalogación de Carmona (2010) y Horta $(2011,2015)$, como procedentes de tierras altas.

\section{LAS BOLSAS CHUSPAS DE AZAPA 15}

Se encontraron 39 chuspas rectangulares hechas de fibra de camélido asociadas a distintos contextos funerarios de Azapa 15. Gracias a nuestra investigación fue posible constatar la presencia de dos tipos distintos: mientras los ejemplares pertenecientes al primero enseñan la pampa como una superficie estructurada sobre la base de dos o más colores contrastantes dispuestos de manera intercalada en anchas franjas verticales, la pampa de las chuspas del segundo tipo posee un solo color. En virtud de lo anterior, en adelante nos referiremos a ellos como Tipo 1 o Pampa Contrastada y Tipo 2 o Pampa Monocroma, respectivamente. En ambos casos la superficie textil es decorada sobre la pampa con franjas verticales de distinto grosor, inscribiéndose en ellas diseños geométricos de variable complejidad. Para caracterizar ambos tipos describiremos y analizaremos sus respectivas distribuciones espaciales, sus técnicas de manufactura y los diferentes motivos en ellos plasmados (fig. 1).

\section{Chuspa Tipo 1 con Pampa Contrastada}

El tipo Pampa Contrastada es el más numeroso. Está conformado por 23 de las 39 chuspas, representando el $60 \%$ del total de la muestra. 


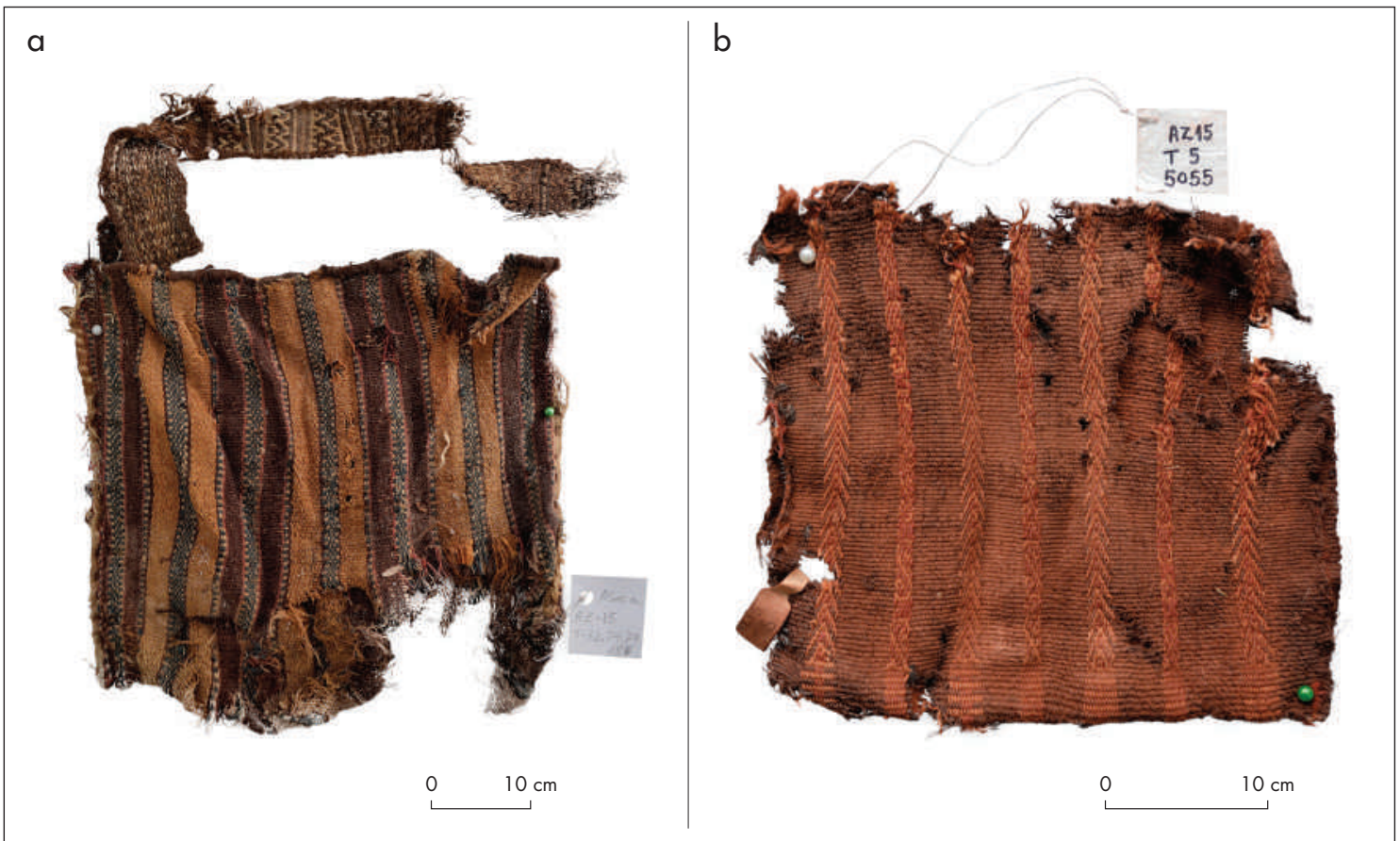

Figura 1: a) ejemplar de Pampa Contrastada no 188, tumba 72, 74 o 79; b) ejemplar de Pampa Monocroma no 5655, tumba 5. Figure 1: a) Contrasted Pampa sample $n^{\circ} 188$, tomb 72, 74 or 79; b) Monochromatic Pampa sample $n^{\circ} 5655$, tomb 5.

\section{Distribución espacial}

La superficie de las chuspas correspondientes al tipo Pampa Contrastada es decorada por franjas verticales de diferente grosor, en cuyo interior se inscriben motivos geométricos. En todos los ejemplares estudiados se observa que, sin excepción, una de estas franjas es dispuesta a modo de eje central, dividiendo la superficie del textil en dos partes iguales. Esta franja central está siempre acompañada por dos listas de menor grosor: la primera a la derecha del eje central, y la segunda a la izquierda. Este patrón -una franja de mayor grosor flanqueada por otras dos más delgadas- se repetirá una y otra vez a lo ancho de la superficie de las chuspas. En lo sucesivo nos referiremos a él con la palabra módulo (figs. 1a y 2).

En el $87 \%$ de los ejemplares estudiados, esto es en 20 de las 23 chuspas de Pampa Contrastada, el eje central presenta el mismo ancho que las franjas que conforman el centro de los demás módulos (fig. 2 a-h). En el 13\% restante se observa un eje central bastante más ancho que todas las demás franjas que surcan la superficie del textil, apreciándose así tres grosores distintos de franjas: una más gruesa para el eje central, otra más delgada para las franjas que constituyen el núcleo de los demás módulos y, finalmente, otras más delgadas aún que acompañan a las franjas centrales (fig. 2 i-k).

En el 91,3\% de los casos -cifra que corresponde a 21 ejemplares- los módulos están completos, es decir, las franjas centrales son siempre flanqueadas por otras más delgadas hacia ambos lados. Se constatan solo dos excepciones en que el lado exterior de las dos franjas anchas más distantes del eje central, y por ende más cercanas a los laterales de las chuspas, no es flanqueado por unas de menor grosor, ubicándose aquellas inmediatamente al lado de las terminaciones (fig. 2b, f).

A continuación, presentamos la reproducción de los motivos y de la distribución espacial de las 23 chuspas de Pampa Contrastada asociadas a Azapa 15. La variante (a) es la más numerosa, existiendo 13 ejemplares exactamente iguales a dicha reproducción. En lo que a las 10 variantes restantes respecta, cada una de ellas presenta un solo ejemplar en el registro arqueológico. De este modo, constatamos que, si bien hay variedad y diversidad, el hecho de que existan 13 ejemplares iguales, cifra que corresponde al 56,5\% del total, evidencia una estandarización interesante. 


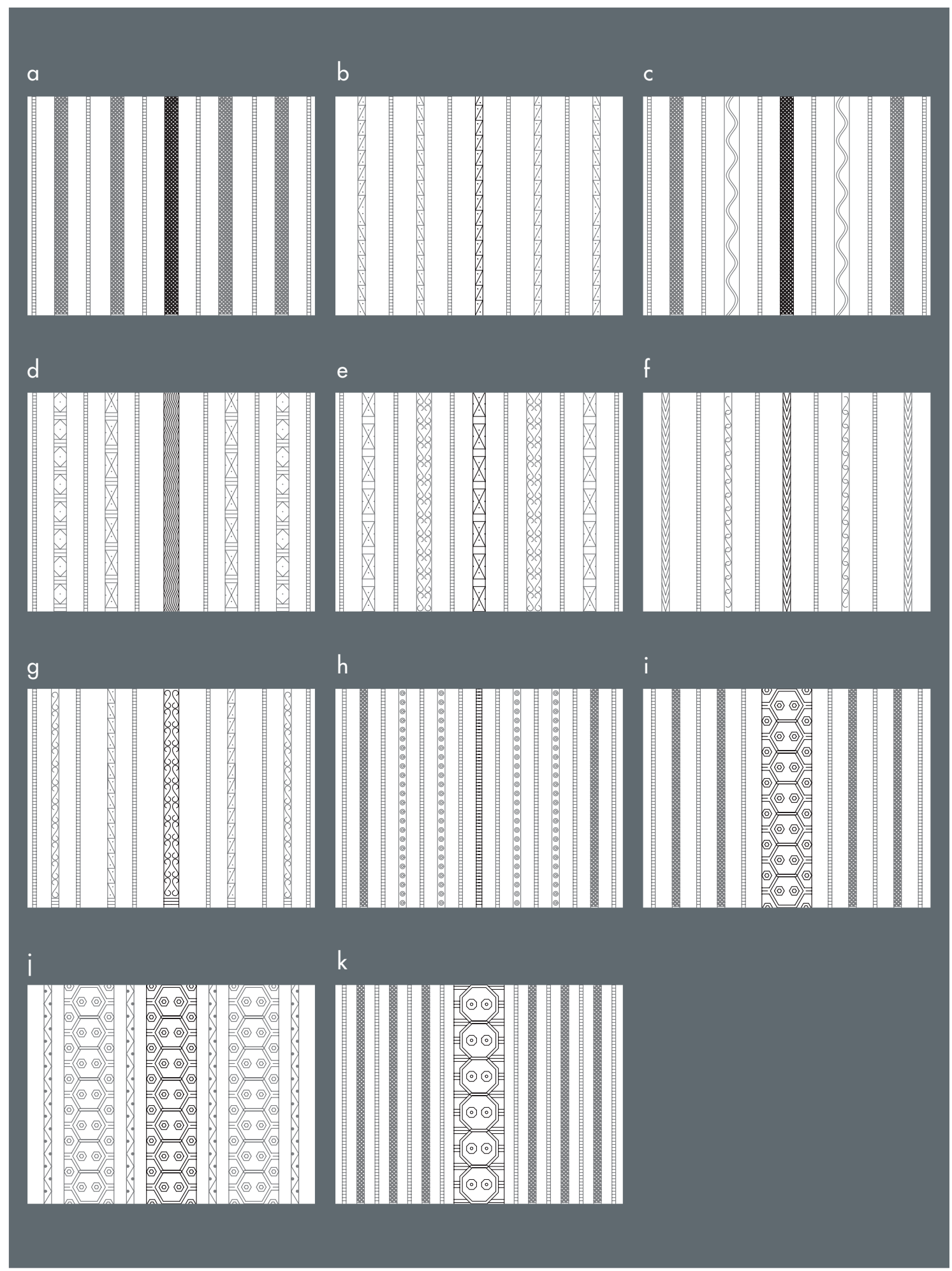

Figura 2. Reproducción de los motivos y de la distribución espacial de las chuspas de Pampa Contrastada asociadas a Azapa 15. Figure 2. Reproduction of motifs and spatial distribution of the Contrasted Pampa chuspas associated with Azapa 15. 
El 87\% de la superficie de los ejemplares estudiados, correspondiente a 20 chuspas, se estructura sobre la base de cinco módulos o, si se quiere, de cinco franjas de mayor grosor y seis más delgadas. Ahora bien, entre estos 20 ejemplares se encuentran las chuspas recién mencionadas que presentan módulos incompletos. Así, en estos dos casos, junto a las cinco franjas de mayor grosor, tenemos solo cinco franjas delgadas en vez de seis. En lo que a las tres chuspas restantes respecta (13\% del total), dos de ellas $(8,6 \%)$ cuentan con siete módulos por superficie y la última $(4,4 \%)$ solo tres (es decir, siete franjas gruesas y ocho delgadas; y tres franjas gruesas y cuatro delgadas, respectivamente). En el caso de los ejemplares con siete módulos, al estar la superficie textil surcada por una mayor cantidad de franjas la distancia entre estas se reduce y la pampa adquiere una menor preeminencia que en los ejemplares con cinco y tres módulos. Ahora bien, en la chuspa de tres módulos la preponderancia de la pampa tampoco es mayor que en el caso recién descrito, pues en aquel las tres franjas centrales adquieren un ancho inusitado al quintuplicar el grosor de las delgadas franjas laterales que conforman los límites de cada módulo (fig. 3).

\section{Técnica}

En el marco del proyecto FONDECYT $1970840,{ }^{5}$ se realizó en 1997 el fichaje técnico de 32 de los 39 ejemplares que conforman el corpus de chuspas de Azapa 15. Seis de las siete chuspas que no fueron incluidas en dicho proyecto corresponden al tipo Pampa Contrastada propuesto ahora por nosotros, por lo que la información entregada a continuación corresponde al estudio de 17 ejemplares.

Invariablemente, la pampa de todas las chuspas analizadas fue manufacturada empleando la técnica de faz de urdimbre y en un $76 \%$ de los casos -13 ejemplares- las bolsas son más anchas que largas, fluctuando sus dimensiones entre los $12 \mathrm{~cm}$ y los $20 \mathrm{~cm}$ de largo, y entre los $15,5 \mathrm{~cm}$ y los $25 \mathrm{~cm}$ de ancho. Mientras que los motivos de 12 chuspas ( $71 \%$ del total) fueron realizados con la misma técnica que las pampas, en cuatro de ellas se observa la utilización de urdimbres complementarias con flotes. En un único ejemplar se recurre a la variante de urdimbres complementarias. Exceptuando un ejemplar, cuya torsión de trama es $4 Z S$ y $2 Z S$, todas las demás tramas y urdimbres presentan una torsión de 2ZS.
Las densidades de tramas y urdimbres fluctúan entre valores medios y altos. En el caso de las tramas, 16 ejemplares ( $94 \%$ del total) poseen densidades medias al contar con seis y diez fibras por $\mathrm{cm}^{2}$ y un ejemplar califica dentro de las densidades altas con 14 fibras. En cuanto a las urdimbres, 11 ejemplares (65\%) exhiben densidades altas y los seis restantes densidades medias al tener sobre 40 , y entre 20 y 39 fibras, respectivamente. En solo cuatro chuspas se observan reparaciones. Al parecer, no existe una relación directamente proporcional entre mayor densidad de los elementos, es decir, entre mayor fineza de la pieza, y remiendos, pues aquellos ejemplares que han sido remendados presentan densidades de urdimbre muy variables $\left(26,40\right.$ y 62 fibras por $\left.\mathrm{cm}^{2}\right)$.

En relación con las terminaciones, en las orillas de urdimbre, es decir, en el borde superior que a la vez hace de boca del textil, se advierte una clara preponderancia de pasadas de cable (11 ejemplares, lo que corresponde a un $65 \%$ del total), en contraposición a dos festones anillados sencillos (11,7\%), dos encandelillados (11,7\%), un festón $(5,8 \%)$ y un festón anillado doble (5,8\%). En las orillas de trama la situación es distinta, pues si bien la terminación del hilván es la más frecuente, esta suele combinarse con distintas técnicas: por un lado se registran tres ejemplares cuyas orillas están terminadas exclusivamente con hilvanes $(17,6 \%)$, por otro lado, cuatro presentan además festones $(23,5 \%)$, dos de ellos anillados sencillos, otros cuatro encandelillados $(23,5 \%)$ y un último ejemplar puntada espina de pez (5,8\%). De los cinco textiles restantes, se distinguen dos con festón anillado sencillo (11,7\%), uno con pasada de cable y puntada de tallo $(5,8 \%)$, uno con encandelillado $(5,8 \%)$, y un quinto y último con encandelillado y festón simple (5,8\%).

¿Cuáles son los colores característicos de las chuspas de Pampa Contrastada? En el 100\% de los casos el color de la trama se limita a distintas tonalidades de café, constituyendo así la policromía una característica exclusiva de los hilados de urdimbre. Beige, blanco, mostaza, crema, distintos tipos de café, rojo, amarillo ocre, azul oscuro y verde petróleo son los colores que se han detectado en las urdimbres de los ejemplares estudiados, siendo los últimos cuatro el resultado de procesos de teñido. La coloración artificial de las fibras es recurrente. Se manifiesta en 14 (76,4\%) de los 17 ejemplares. Ahora bien, ¿cuáles son los colores utilizados con mayor frecuencia? En la totalidad de las chuspas de Pampa Contrastada, el color café en sus distintas tonalidades es el más recurrente, seguido por los colores rojo, crema y amarillo 


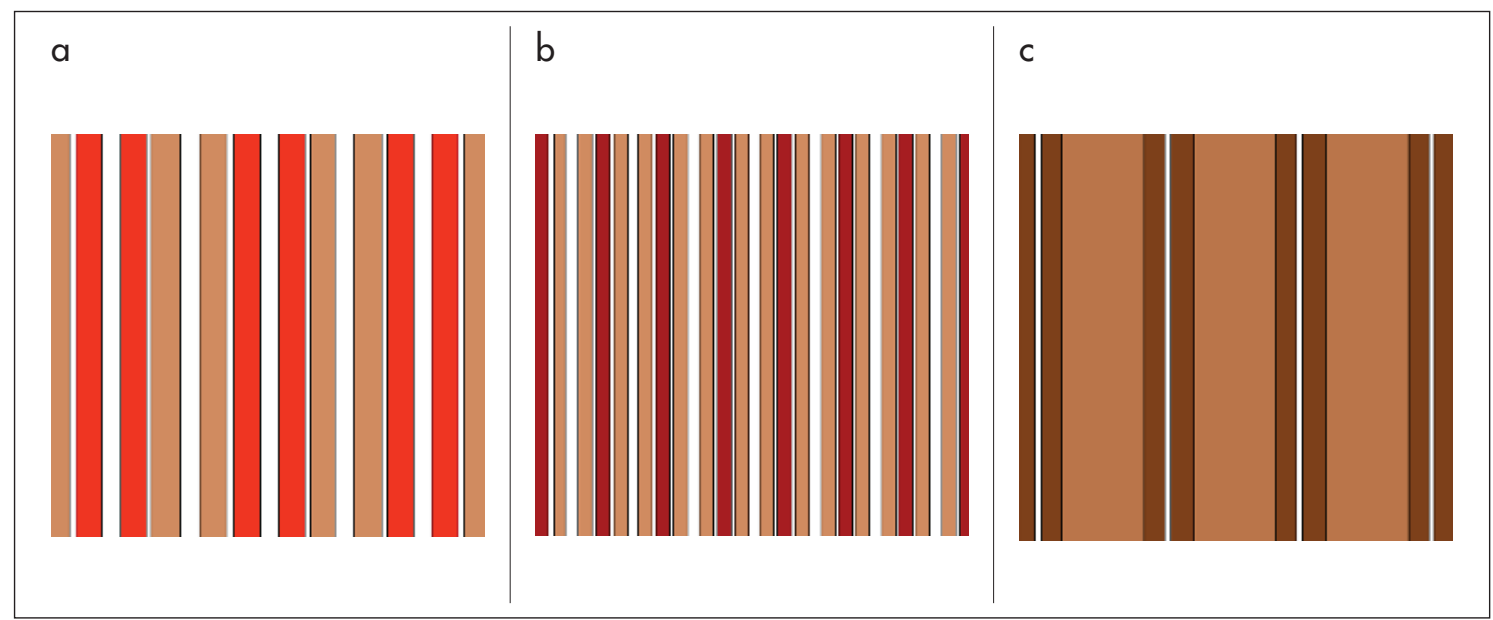

Figura 3. Ejemplares de Pampa Contrastada de: a) cinco módulos; b) siete módulos; c) tres módulos Figure 3. Contrasted Pampa samples of: $a)$ five stripes; $\boldsymbol{b}$ ) seven stripes; $c$ ) three stripes.

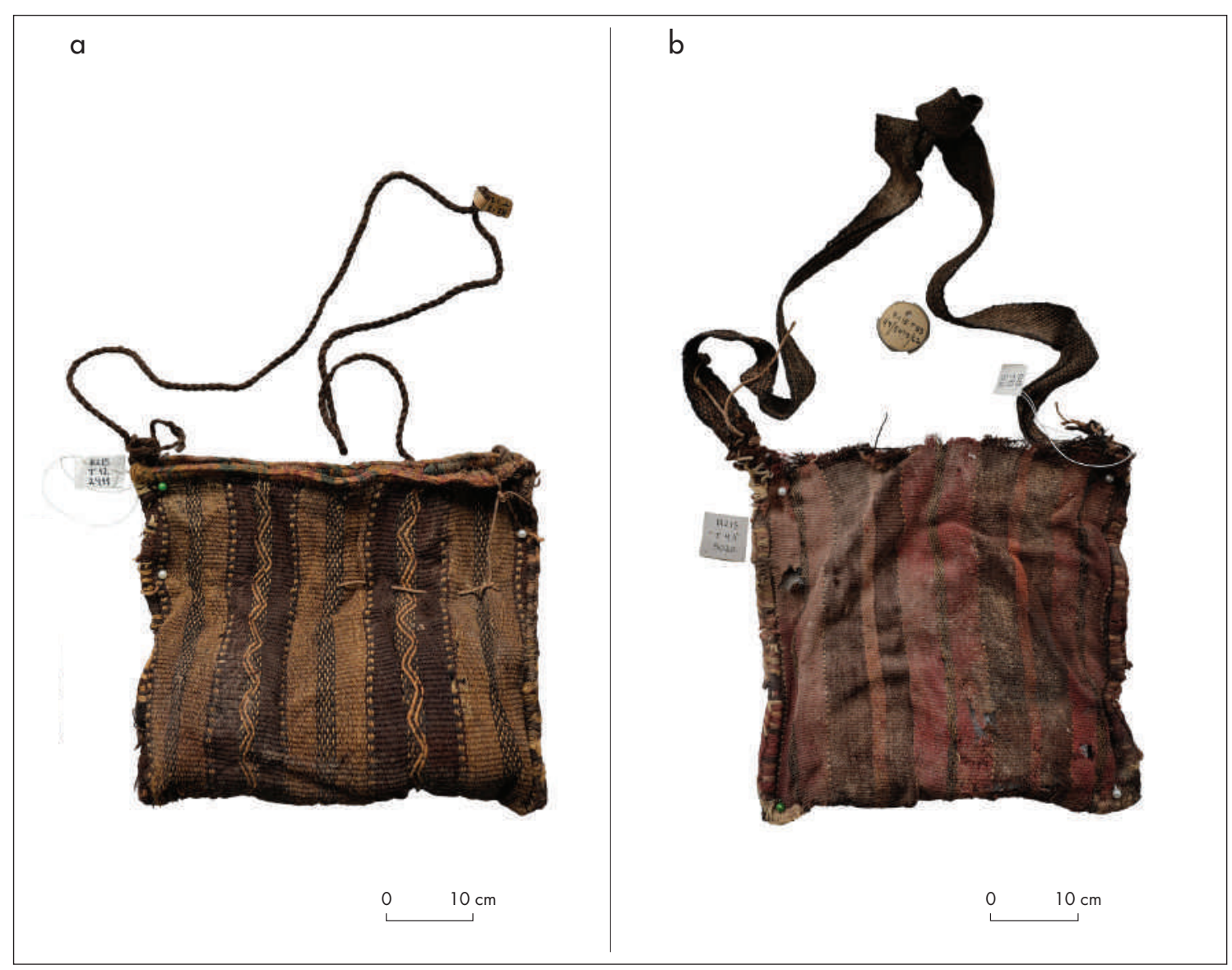

Figura 4. Ejemplares de Pampa Contrastada: a) con cuerda, n² 2411, tumba 12; b) con asa, $\mathrm{n}^{\circ}$ 5020, tumba 93. Figure 4. Contrasted Pampa samples: $a$ ) with cord, $n^{\circ} 2411$, tomb 12; b) with handle, $n^{\circ}$ 5020, tomb 93. 
ocre, presentes en $15(88,2 \%), 13(76,4 \%)$ y $12(70,5 \%)$ ejemplares respectivamente. Bastante menos frecuentes son las fibras de color beige, blanco, azul oscuro, verde petróleo y mostaza. ¿Existen colores exclusivos para las pampas y otros para las líneas verticales y de los motivos en ellas inscritos? Los colores contrastantes que, como ya mencionamos, alternados entre sí constituyen la pampa del textil representan en el $88,2 \%$ de los casos distintos tonos de café. En las dos bolsas chuspas que constituyen el 11,8\% restante se observan, de manera excepcional, listas verticales rojas y listas verticales color verde petróleo respectivamente, las que se alternan en ambos casos con franjas color café. De esta manera, se observa que en la gran mayoría de los casos las fibras teñidas se restringen a las franjas verticales que decoran la pampa contrastada y a los diseños.

De los 23 ejemplares que conforman el total del corpus de Pampa Contrastada, solo seis cuentan con asas (26\%). Otros seis (26\%) enseñan una cuerda delgada en el extremo superior de los laterales, allí donde en caso de existir asas estas se conectan con el cuerpo de las bolsas destinado a amarrar la boca de las chuspas para evitar que el contenido se desparrame. Por desgracia, debido a una cuestión de conservación, no podemos saber con certeza si los 11 ejemplares restantes tenían asas o cuerdas como los ya mencionados (fig. 4). Por otra parte, ¿qué sabemos del contenido de estas chuspas? 10 de las 17 bolsas registradas contenían restos de material vegetal: nueve con hojas de coca y una con restos de maíz). En otra se encontró un atado de palitos amarrados entre sí, en otra lana sin hilar, y en la última, restos de cabello humano junto a una bolsa hecha probablemente de vejiga de animal.

\section{Motivos}

A diferencia del análisis técnico que se restringió a 17 ejemplares, en este apartado nos referiremos a los motivos que decoran la superficie de las 23 chuspas del tipo Pampa Contrastada asociadas a Azapa 15. Como hemos dicho, los motivos inscritos al interior de las franjas verticales son siempre formas geométricas de variable complejidad. Si bien, se detectaron 16 motivos diferentes, cada franja es decorada con un solo diseño que se repite a lo largo hasta llenarla. A continuación, describiremos los motivos inscritos en el interior de las franjas más delgadas, luego los de las listas más anchas y finalmente los de la franja central o eje del textil.

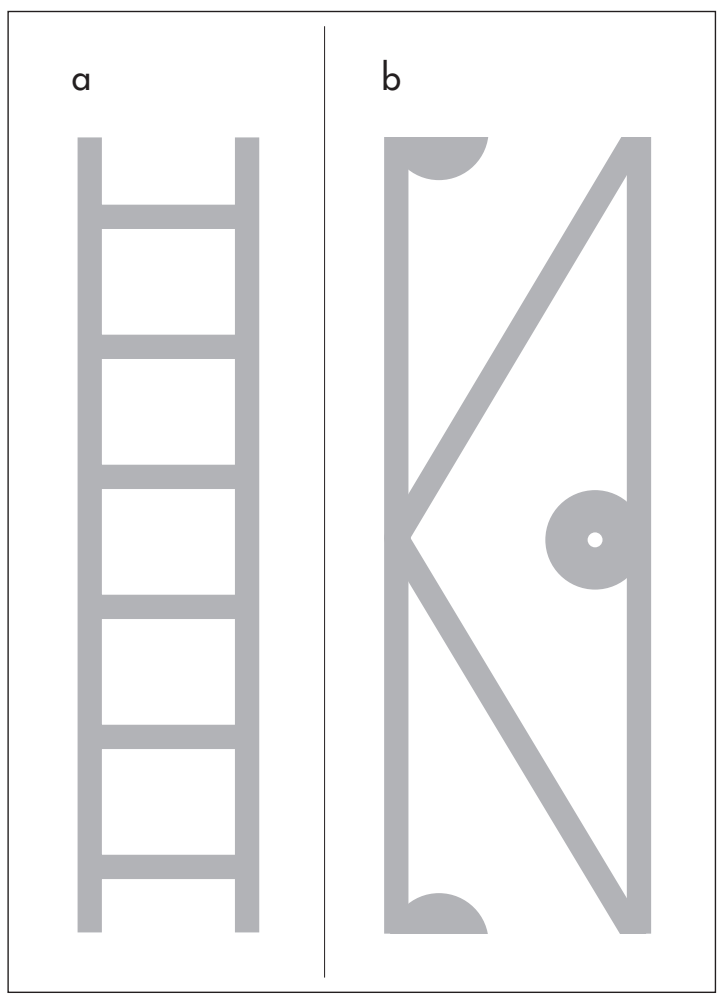

Figura 5: a) k’utu; b) zigzag con círculos concéntricos. Figure 5: a) k'utu; b) zig zag with concentric circles.

El motivo en zigzag con círculos concéntricos y el k’utu -llamado también peinecillo-son los únicos diseños que se inscriben en el interior de las franjas delgadas de las chuspas de Pampa Contrastada (fig. 5). Hay que destacar que ambos motivos nunca aparecen juntos en una misma chuspa y que, mientras el zigzag está presente tan solo en la chuspa de tres módulos, el $k^{\prime} u t u$ aparece en los restantes 22 ejemplares (4,3\% y 95,6\% del total, respectivamente).

Si analizamos en detalle los motivos inscritos en el interior de las franjas de mayor grosor, es decir, aquellas que se intercalan con las listas delgadas, constataremos de inmediato que presentan una variedad mayor de diseños que en el caso anterior. Los motivos identificados son: jaspeados, motivos en " $Z$ " con dos puntos, distintos tipos de volutas en " $S$ " -simples, concatenadas y enfrentadas-, relojes de arena con cuatro puntos, círculos concéntricos, motivos ondulantes, hexágonos inscritos entre dos franjas horizontales, y hexágonos de gruesos trazos con dos hexágonos concéntricos inscritos en su interior (fig. 6). 


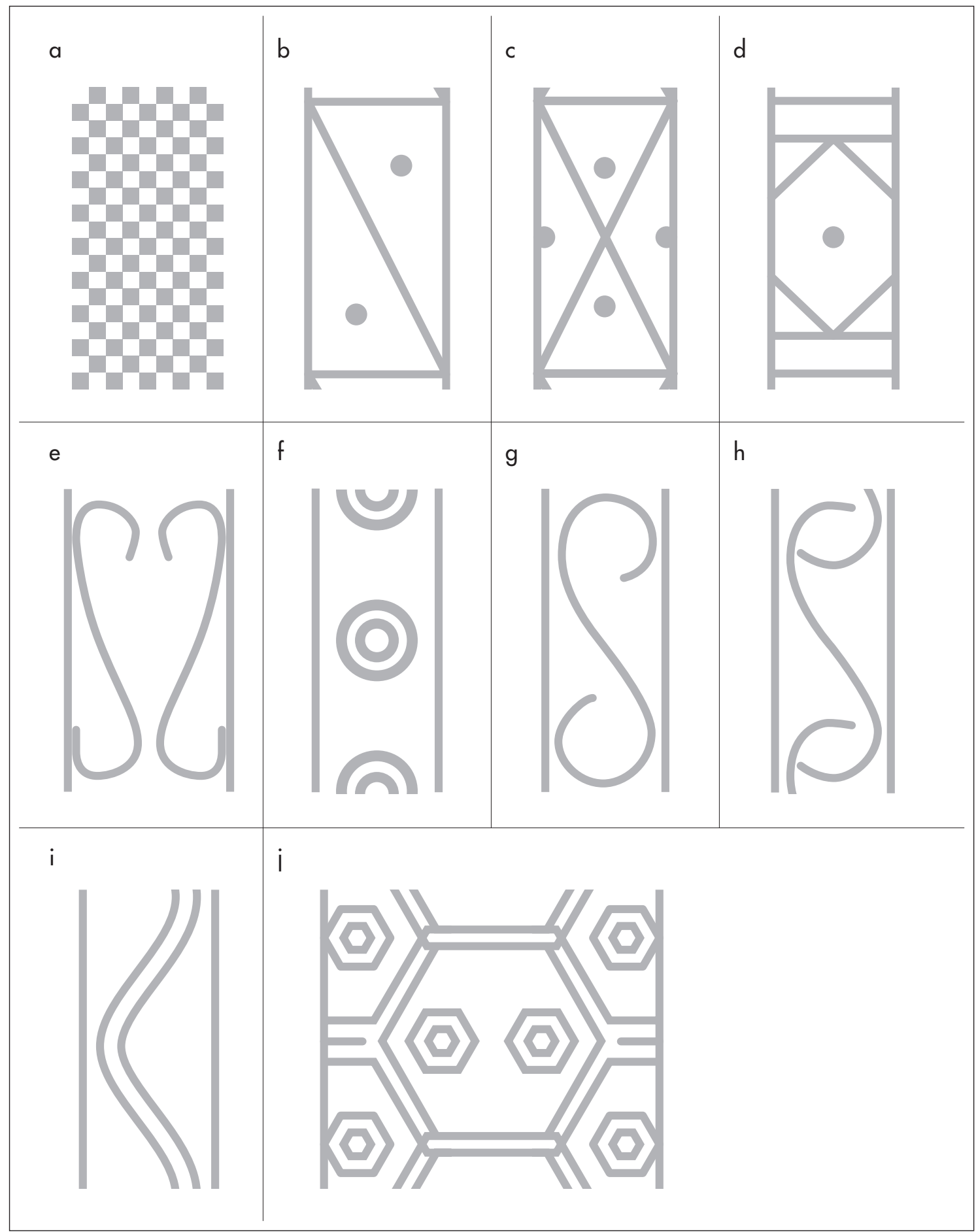

Figura 6: a) jaspeado; b) motivo en $\mathrm{Z}$ con dos puntos; c) reloj de arena con cuatro puntos; d) hexágono inscrito entre dos franjas horizontales; e) volutas en $\mathrm{S}$ enfrentadas; f) círculos concéntricos; $\mathrm{g}$ ) voluta en $\mathrm{S}$ sencilla; $\mathbf{h}$ ) voluta en $\mathrm{S}$ concatenada; i) motivo ondulante; j) hexágono de gruesos trazos con hexágono concéntrico inscrito en su interior. Figure 6: $\boldsymbol{a}$ ) marbled; $\boldsymbol{b}$ ) $Z$ motif with two dots; c) hourglass with two dots; $d$ ) hexagon inscribed between two horizontal stripes; $\boldsymbol{e}) S$-shaped volutes facing each other; $f$ ) concentric circles; $g$ ) single S-shaped volute; $h$ ) concatenated S-shaped volute; $i)$ undulating pattern; $j$ ) thick-stroke hexagon with concentric hexagon inside. 


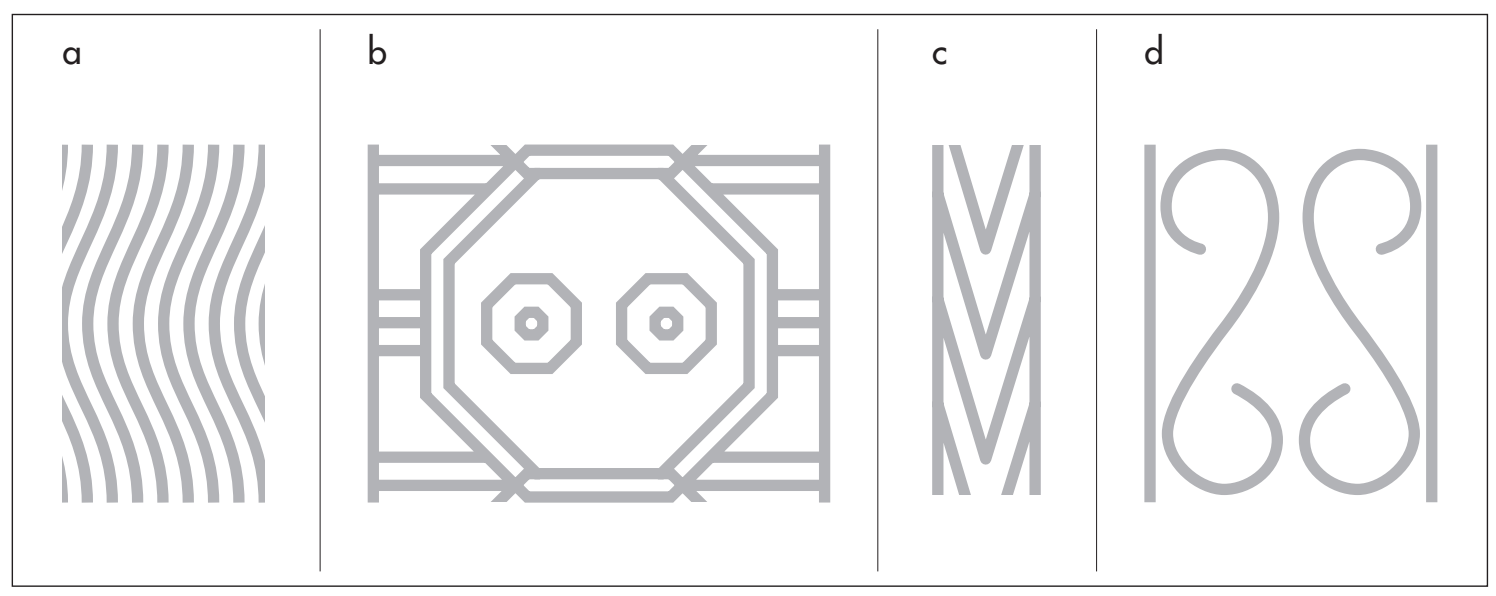

Figura 7: a) motivos ondulantes; b) octógono con dos octógonos concéntricos inscritos en su interior; c) chevrón; d) dos volutas en $\mathrm{S}$ enfrentadas por la espalda. Figure 7: $\boldsymbol{a}$ ) undulating patterns; $\boldsymbol{b}$ ) octagon with two concentric octagons inside; $\boldsymbol{c}$ ) chevron; $d$ ) S-shaped volutes back to back.

Con excepción del motivo jaspeado, del reloj de arena y del motivo en " $Z$ ", presentes en $17(73 \%)$, en dos $(8,6 \%)$ y dos $(8,6 \%)$ chuspas respectivamente, los demás diseños aparecen en un solo ejemplar. Por ello, los motivos de las franjas anchas y los de las franjas delgadas que las flanquean son siempre distintos.

Cabe entonces preguntarse, ¿cuáles son los motivos que aparecen en el eje central? Hemos identificado ocho formas geométricas distintas, cuatro de las cuales nos son familiares pues aparecen también en las franjas anchas y en las franjas delgadas recién mencionadas. Los motivos compartidos por las franjas anchas son los siguientes: el motivo jaspeado, que es el más usual ya que está presente en 14 ejemplares; el hexágono de gruesos trazos con dos hexágonos concéntricos inscritos en su interior, detectado en dos chuspas; y el motivo en " $Z$ " y el reloj de arena, cada uno en un ejemplar. Coincidiendo con la decoración de las franjas delgadas, en un ejemplar se observa un k'utu a modo de franja central, el cual es flanqueado a su vez por otras franjas más delgadas decoradas con el mismo motivo.

Respecto de los motivos que aparecen de manera exclusiva en el eje central, podemos dar cuenta de algunos ondulantes, un octógono con dos octógonos concéntricos inscritos en su interior, un chevrón y dos volutas en "S" enfrentadas por la espalda (fig. 7). Si bien el motivo ondulante múltiple, el octógono y las volutas son exclusivos, es innegable su parecido y familiaridad con el motivo ondulante simple, el hexágono con dos hexágonos concéntricos inscritos y las distintas variedades de volutas descritas para el caso de las franjas gruesas.

\section{Chuspa Tipo 2 con Pampa Monocroma}

El tipo Pampa Monocroma es el menos numeroso, representando un $30,7 \%$ del total. ${ }^{6}$ Está conformado por 12 de las 39 chuspas asociadas a Azapa 15.

\section{Distribución espacial}

Tal como hemos dicho, la pampa de las chuspas correspondiente al segundo tipo presenta un solo color, al igual que en el tipo Pampa Contrastada, y se encuentra surcada por franjas verticales en cuyo interior se inscriben distintos motivos geométricos.

Mientras el 50\% de las chuspas enseña cinco franjas (figs. 8 a y $9 a$ ), el $41,6 \%$ presenta siete (fig. 8 b) y el $8,4 \%$ ocho. Así, de manera coincidente con el Tipo 1, la mayoría de los ejemplares (11 de los 12, lo que corresponde al $91,6 \%$ del total de la muestra) presentan una franja a modo de eje central que divide el textil en dos lados iguales. Solo el ejemplar de ocho franjas exhibe dos líneas centrales iguales. Ahora bien, a pesar de esta particularidad, la chuspa en cuestión se ciñe a la norma al dividir este eje central del textil en dos partes iguales. En aquellos ejemplares que presentan cinco franjas, la pampa tiene mayor preponderancia pues, a pesar de ser menor en cantidad, no aumentan su grosor. Así, las bandas de las chuspas monocromas de cinco franjas se distribuyen evidentemente de manera más espaciada, diferenciándose de lo que ocurre en el tipo Pampa 


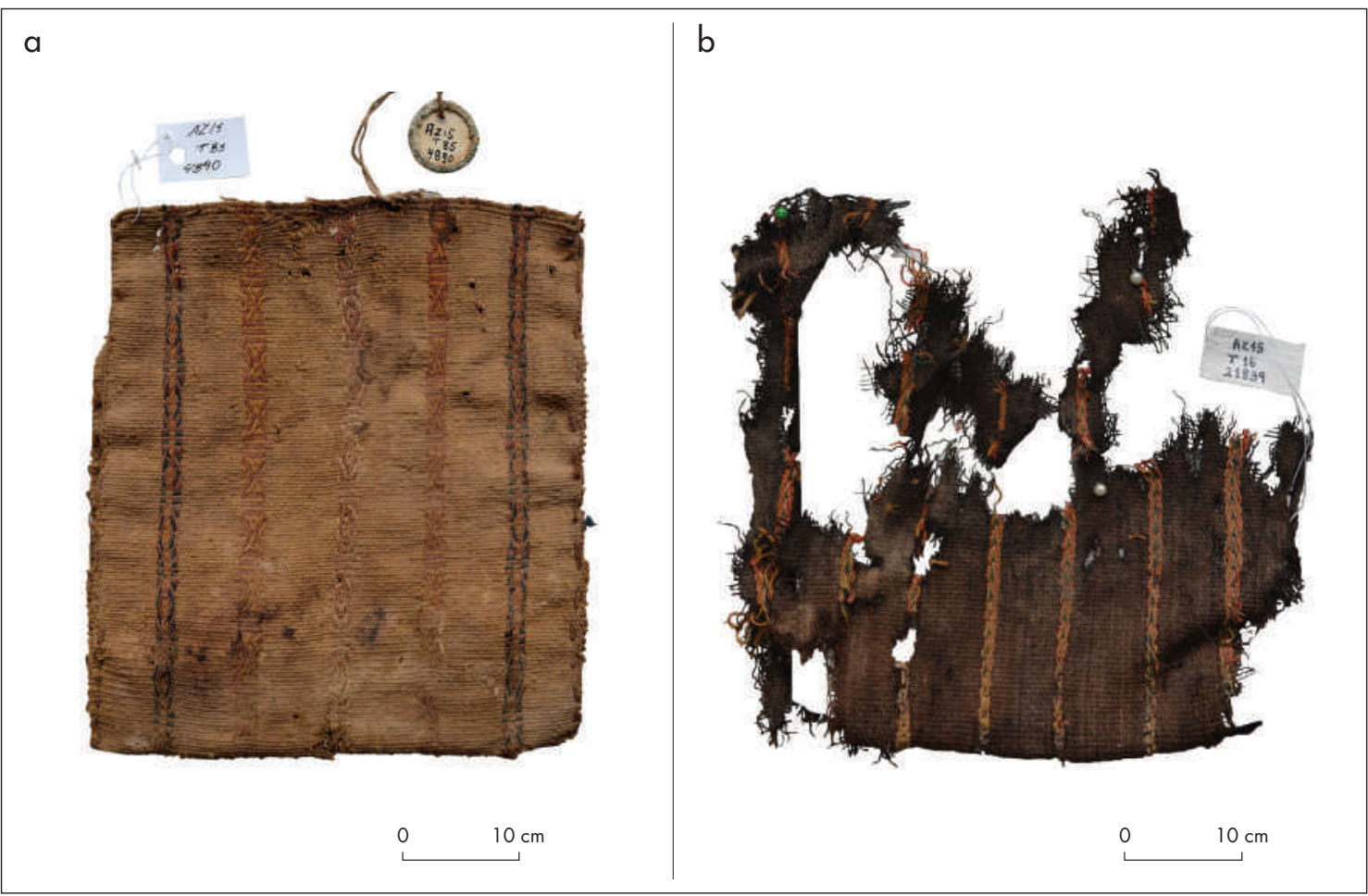

Figura 8. Ejemplares de Pampa Monocroma con: a) cinco franjas, no 4890, tumba 85; b) siete franjas, $\mathrm{n}^{\circ} 21.839$, tumba 16 . Figure 8 . Monochromatic Pampa samples with: a) five stripes, $n^{\circ} 4890$, tomb 85 ; b) seven stripes, $n^{\circ} 21.839$, tomb 16.

Contrastada, en el que el menor número de módulos hace que estos sean más gruesos, ocultando de igual manera gran parte de la pampa del textil.

Ocho de los doce de los ejemplares monocromos $(66,6 \%-)$ presentan la totalidad de sus franjas del mismo grosor, mientras que el en $30,4 \%$ restante los ejes centrales son más anchos que las demás franjas. En este último grupo se encuentra aquella chuspa de ocho franjas que tiene un eje central. Vemos así que la preponderancia de los ejes centrales está más vinculada a los motivos en ella inscritos que al ancho de sus respectivas franjas.

\section{Técnica}

Para el análisis tecnológico nos basamos igualmente en los datos recabados por el proyecto FONDECYT ya mencionado, el cual registró 11 de las 12 chuspas de Pampa Monocroma. Estos 11 ejemplares serán considerados en el presente apartado como equivalentes al $100 \%$ de la muestra.

Del mismo modo que los ejemplares del tipo Pampa Contrastada, la superficie del 100\% de las chuspas de
Pampa Monocroma fue manufacturada con la técnica de faz de urdimbre. En seis ejemplares $(54,5 \%)$ las bolsas son más anchas que largas y sus dimensiones fluctúan entre los $11 \mathrm{~cm}$ y los $18,5 \mathrm{~cm}$ de largo, y entre los 11,5 $\mathrm{cm}$ y los $22 \mathrm{~cm}$ de ancho. En relación con la elaboración de los diseños, mientras que los motivos de dos chuspas ( $18,1 \%$ del total) fueron realizados con la técnica de faz de urdimbre, en los nueve ejemplares restantes la técnica fue de urdimbres complementarias con flotes.

Por otra parte, las densidades de tramas y urdimbres fluctúan entre valores medios y altos. En el caso de las tramas, siete ejemplares $(63,6 \%)$ presentan densidades medias al tener entre seis y diez fibras por $\mathrm{cm}$, cuatro ejemplares (36,3\%) tienen densidades altas al tener más de diez. En cuanto a las urdimbres, ocho ejemplares $(72,7 \%)$ presentan densidades altas y los tres restantes medias $(27,2 \%)$.

Respecto a las terminaciones, en las orillas de urdimbre se observa, al igual que en el tipo anterior, una clara preponderancia de pasadas de cable con nueve ejemplares, cifra que corresponde al $81,8 \%,{ }^{7}$ en contraposición a un festón anillado sencillo (9\%) y un 
festón anillado doble (9\%). Por otra parte, la terminación del hilván es la más frecuente en la Pampa Monocroma -otra coincidencia con la Pampa Contrastada-. No obstante, suele combinarse con distintas técnicas, como lo atestiguan los cuatro ejemplares cuyas orillas están hechas exclusivamente de hilvanes (36,3\%), los dos que presentan además encandelillados (18,1\%), otro que incluye un festón y él último un festón y un encandelillado de manera simultánea. En las tres chuspas restantes que no presentan hilván, se distingue una con encandelillado $(27,2 \%)$ y dos con festón anillado doble (18,1\%).

¿Cuáles son los colores característicos de las chuspas de Pampa Monocroma? El color de la trama se restringe a distintos tonos de café en la totalidad de los ejemplares analizados, de igual forma que los de Pampa Contrastada. Nuevamente la policromía constituye una característica exclusiva de los hilados de urdimbre. Los colores detectados en las urdimbres son blanco, mostaza, crema, variadas tonalidades de café, rojo, amarillo ocre, azul y distintos tonos de verde, observándose la coloración artificial de las fibras en el 100\% de los ejemplares (con algún color de los mencionados). En relación a los colores utilizados con mayor frecuencia, el color café en sus distintas tonalidades ha sido identificado en el 100\% de las chuspas de Pampa Monocroma. Al igual que en los ejemplares de Pampa Contrastada, el uso del café es seguido por los colores rojo, crema y amarillo ocre, presentes en diez $(83,3 \%)$, nueve $(75 \%)$ y nueve $(75 \%)$ ejemplares, respectivamente. El azul, por su parte, está presente en seis ejemplares (50\%), el verde en cuatro $(33,3 \%)$, el blanco en tres (25\%) y el mostaza en uno $(8,3 \%)$. Al igual que en el caso anterior, nos preguntamos si hay colores que se restrinjan a la manufactura de las pampas y otros a la realización de las franjas verticales y a los motivos en ellas inscritos. La pampa siempre es café y no presenta colores teñidos, a diferencia de lo ocurrido en el tipo Pampa Contrastada, en que dos ejemplares se presentan rojo y verde intercalados con distintos tonos de café. En lo que a las franjas verticales y a sus motivos respecta, estas se realizan con los ocho colores señalados.

A diferencia de los ejemplares de Pampa Contrastada, aquí no se ha detectado la presencia de asas. Ahora bien, el 25\% enseña aquel cordel delgado que ya identificamos para algunos ejemplares del tipo anterior, destinado a cerrar la boca del textil (fig. 9). Respecto del contenido de estas chuspas, se establece que cinco de las once chuspas analizadas presentaban restos de material vegetal (en tres de ellas había restos de maíz y en dos hojas de coca) y una sexta un polvillo color rojo. Por último, diez ejemplares exhiben torsiones de urdimbre y trama de 2ZS. Escapando a la regla, el onceavo ejemplar tiene una torsión de urdimbre de S y 2ZS, y una torsión de trama de 1S. Por otra parte, cabe destacar que no se detectan chuspas con reparaciones.

\section{Motivos}

A continuación, describiremos los motivos de 11 de las 12 bolsas que conforman el corpus del tipo Pampa Monocroma pues, si bien se distingue con claridad la distribución espacial de la totalidad de ellas, en un ejemplar los motivos no logran apreciarse debido a problemas de conservación. De este modo, en el presente apartado serán considerados nuevamente 11 ejemplares como equivalentes al $100 \%$ de la muestra.

Del mismo modo que en el tipo Pampa Contrastada, en cada franja se repite un mismo motivo. Los motivos detectados en las chuspas analizadas son 14, siendo ocho de ellos compartidos con los ejemplares del Tipo o Pampa Contrastada. Aunque en dicho tipo tiene poca representatividad, el primero de estos motivos compartidos es el chevrón, presente en cuatro de las 11 chuspas, es decir, en un $36,3 \%$. Le siguen la voluta en "S" sencilla, la voluta en " $S$ " concatenada, las volutas en "S" enfrentadas y el reloj de arena, apareciendo cada uno de ellos en dos ejemplares, respectivamente (18,1\%). Estos cuatro motivos aparecen con mayor frecuencia en el tipo Pampa Monocroma que en el Pampa Contrastada, pues en este último grupo cada uno de ellos se encuentra representado por un solo ejemplar. El zigzag con círculos concéntricos y el k’utu han sido detectados cada uno en una chuspa (9\%). Consideramos importante enfatizar que la poca representatividad del $k^{\prime} u t u$ o peinecillo marca una diferencia significativa con el tipo Pampa Contrastada, donde el motivo en cuestión aparecía en 22 de los 23 ejemplares analizados, cifra que corresponde al 95,6\%.

En cuanto a los motivos exclusivos del tipo Pampa Monocroma, hemos detectado seis figuras geométricas de variable complejidad. Las tres primeras corresponden a variantes del rombo: rombo con punto, rombo con cuatro puntos y rombo con cuatro círculos y rombo concéntrico. Los tres motivos tienen en común que una figura geométrica de importancia secundaria -puntos y rombo de menor tamaño- se encuentran inscritos en el interior del rombo principal. Se diferencian del rombo 


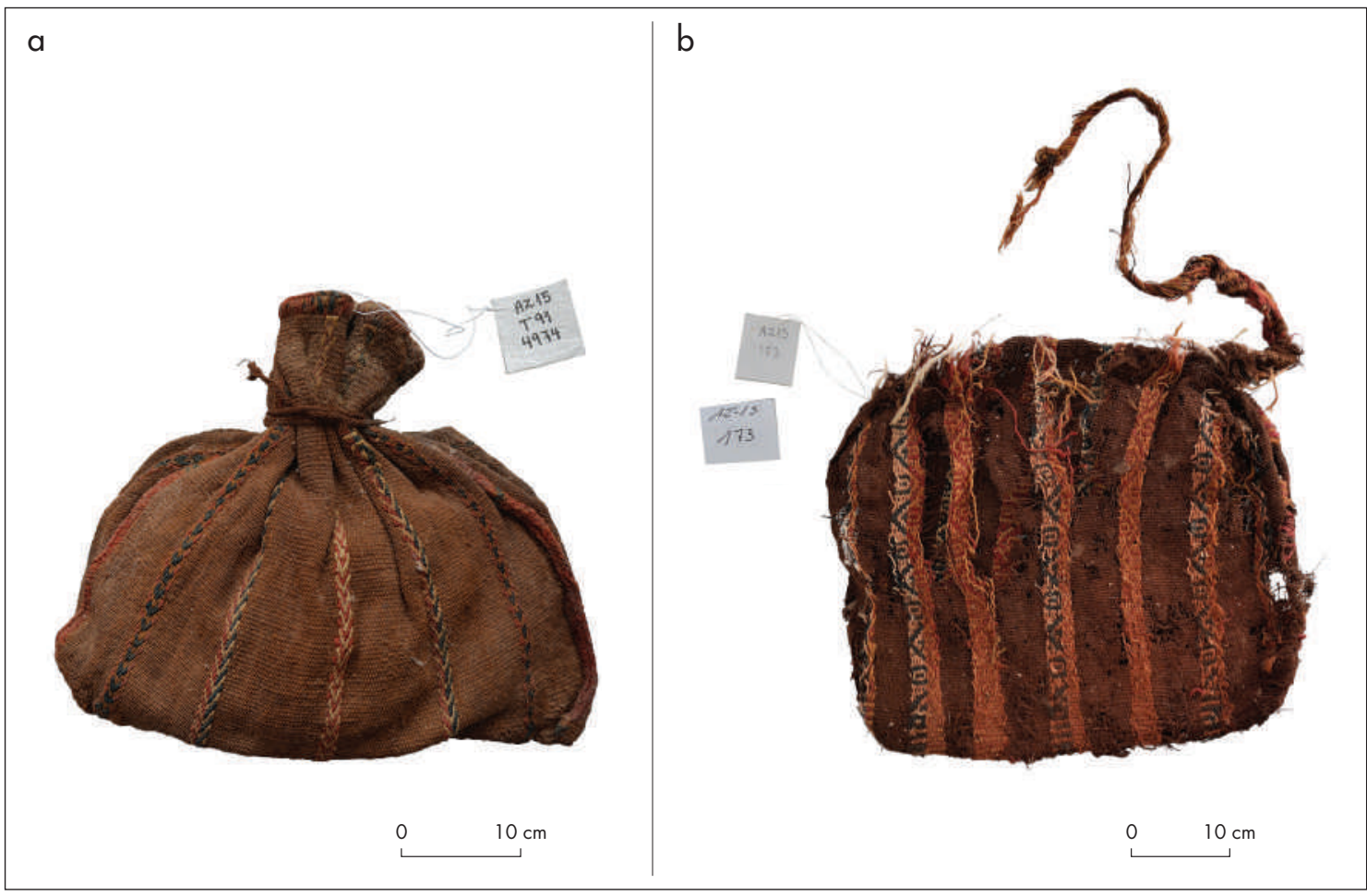

Figura 9. Ejemplares de Pampa Monocroma con cordel: a) no 4974, tumba 91; b) nº 173, tumba 12 o 15. Figure 9. Monochromatic Pampa samples with cord: a) no 4974, tomb 91; b) no 173 , tomb 12 or 15.

presente en los ejemplares de tipo Pampa Contrastada en que estos tres no están dispuestos entre franjas verticales. Emparentados con las variantes de rombos, tenemos un hexágono con hexágono concéntrico y un octógono con rombo concéntrico, ambas figuras dentro de dos y una franja horizontal, respectivamente. Por último, se aprecian volutas en "S" concatenadas y opuestas, es decir, volutas en "S" que, enfrentadas por las espaldas, están conectadas con las volutas que las anteceden y con las que las suceden. Curiosamente, del mismo modo que los tres tipos de rombos mencionados, el hexágono con hexágono concéntrico, el octógono con octógono concéntrico y las volutas en "S" concatenadas y opuestas presentan puntos en distintas partes del diseño. Mientras los dos primeros los tienen en el centro exacto del motivo, las volutas en "S" se ven acompañadas de puntos allí donde comienzan sus cabezas (fig. 10).

¿Con qué frecuencia aparecen los motivos exclusivos ya mencionados? Con excepción del octógono con rombo concéntrico, detectado en dos ejemplares $(18,1 \%)$, el resto de las figuras geométricas aparecen una sola vez ( $9 \%$ del total cada una).
En relación con lo mismo nos preguntamos si presentan los motivos dispuestos en las franjas centrales de los ejemplares de Pampa Monocroma alguna particularidad o exclusividad que permita establecer la existencia de una preponderancia del eje central respecto de las franjas laterales. En tres ejemplares $(27,2 \%)$ los motivos son iguales para todas las franjas verticales: uno de ellos presenta zigzags con círculos concéntricos y los dos siguientes chevrones (fig. 11 a, f, i). Por otra parte, en el $45,4 \%$ de los ejemplares se aprecian dos motivos por chuspa, uno de ellos dispuesto en las franjas pares $y$ el otro en las franjas impares, sin motivos exclusivos para la franja central. Contamos con las siguientes combinaciones: un rombo con punto y chevrón, un octógono con rombo concéntrico y reloj de arena, un chevrón y voluta en "S" sencilla, y dos ejemplares con volutas en " $S$ " concatenadas y volutas en " $S$ " enfrentadas (fig. $11 \mathrm{c}-\mathrm{e}, \mathrm{g}, \mathrm{h}$ ).

En las tres chuspas que constituyen el 27,3\% restante se aprecian tres motivos distintos: uno de ellos dispuesto en la franja central y los otros dos, al igual que en el $45,4 \%$ recién mencionado, en las franjas 


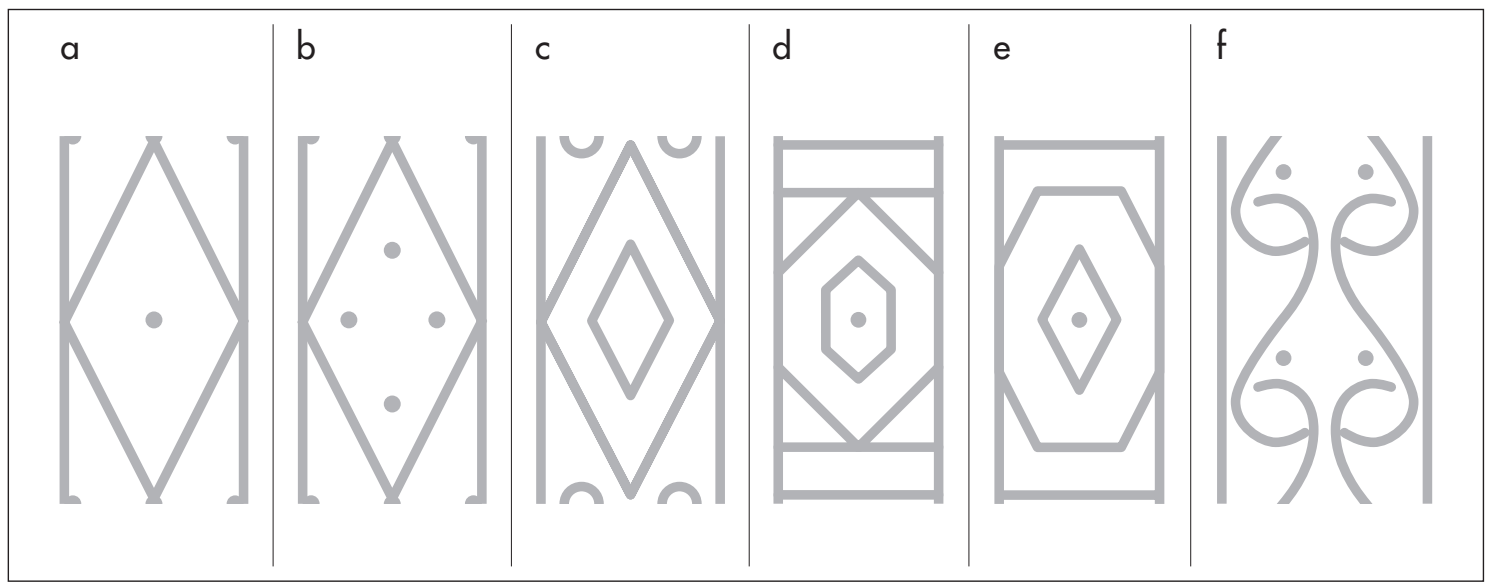

Figura 10: a) rombo con punto; b) rombo con cuatro puntos; c) rombo con cuatro círculos y rombo concéntrico; d) hexágono con hexágono concéntrico; e) octógono con rombo concéntrico; f) volutas en S concatenadas y opuestas. Figure 10: a) diamond shape with dot; $\boldsymbol{b}$ ) diamond shape with four dots; $\boldsymbol{c}$ ) diamond shape with four circles and concentric diamond; $\boldsymbol{d}$ ) hexagon with concentric hexagon; $\boldsymbol{e}$ ) octagon with concentric diamond; $f$ ) opposed, concatenated S-shaped volutes.

pares e impares, respectivamente. La franja central del primer ejemplar está conformada por las volutas en "S" concatenadas y opuestas, acompañadas por el rombo de cuatro puntos y por el motivo en " $Z$ ". La del segundo ejemplar contiene al octógono con rombo concéntrico, acompañado por el reloj de arena y por el hexágono con hexágono concéntrico. En el tercer ejemplar -aquella chuspa que de manera excepcional cuenta con un doble eje central- observamos en el medio al rombo con cuatro círculos y rombo concéntrico, flanqueado por volutas en "S" y k'utus. Escapando una vez más de la norma, en este último ejemplar los dos motivos acompañantes de la franja central no se intercalan, pues los k'utus se restringen exclusivamente a la franja vertical que corre paralela al término del textil. ${ }^{8}$

A continuación, reproducimos los motivos y la distribución espacial de 11 chuspas de Pampa Monocroma. Cabe destacar que la variante (h) es la más numerosa, pues dos ejemplares asociados a Azapa 15 presentan la misma combinación de motivos (fig. 11h).

En definitiva, al comparar los tipos Pampa Contrastada y Pampa Monocroma podemos concluir lo siguiente:

1. Confeccionadas en fibra de camélido, las bolsas chuspas asociadas a Azapa 15 son rectangulares y el 76\% y 54\% de los ejemplares de Pampa Contrastada y Pampa Monocroma, respectivamente, son más anchos que largos. El tamaño de ambos tipos es similar: mientras las dimensiones del Tipo 1 fluctúan entre los $12 \mathrm{~cm}$ y los $20 \mathrm{~cm}$ de largo, y entre los 15,5 $\mathrm{cm}$ y los $25 \mathrm{~cm}$ de ancho, las del Tipo 2 oscilan entre los $11 \mathrm{~cm}$ y los $18,5 \mathrm{~cm}$ de largo, y entre los $11,5 \mathrm{~cm}$ y los $22 \mathrm{~cm}$ de ancho.

2. La superficie de ambos tipos se estructura según franjas verticales de número y ancho variables. Ahora bien, la distribución de dichas franjas en el espacio es muy distinta en cada tipo, ciñéndose cada uno a rígidos patrones estandarizados. Mientras que en el tipo Pampa Contrastada se observan módulos, en el tipo Pampa Monocroma solo se observan franjas de carácter individual que no conforman módulos. A pesar de esta diferencia, los dos tipos suelen presentar un eje central que divide la superficie del textil en dos partes iguales, premisa que no se cumple en ningún ejemplar del tipo Pampa Monocroma. En ambos tipos, la franja central suele tener el mismo ancho que las franjas laterales (87\% y $66,6 \%$ de los ejemplares en el Tipo 1 y el Tipo 2, respectivamente).

3. El $100 \%$ de las pampas de las chuspas analizadas fue manufacturado empleando la técnica de faz de urdimbre. En lo que a los motivos respecta, el $71 \%$ del tipo Pampa Contrastada fue realizado con la misma técnica que las pampas, mientras que el 81,8\% de los ejemplares de Pampa Monocroma fue hecho con la técnica de urdimbres complementarias con flotes. 


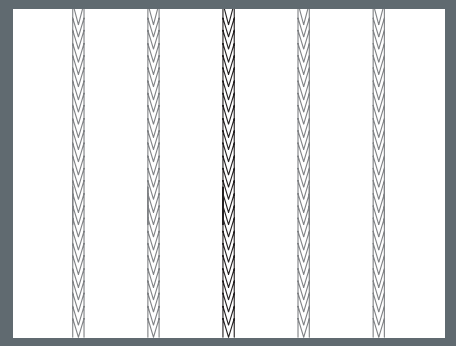

b

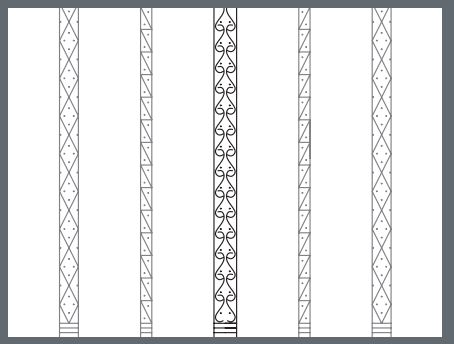

C

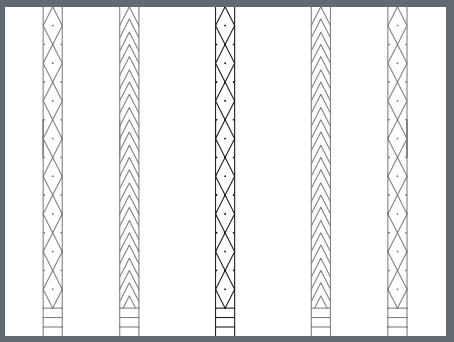

$d$

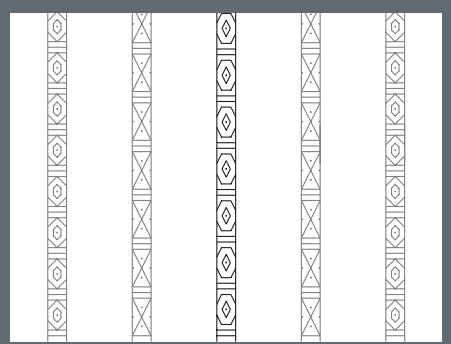

e

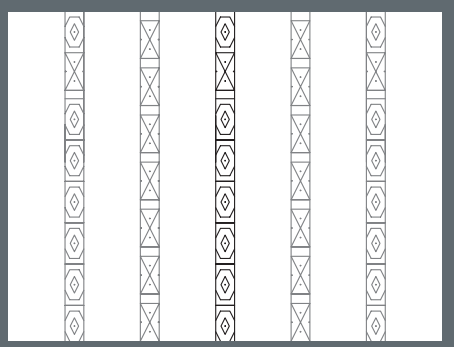

f

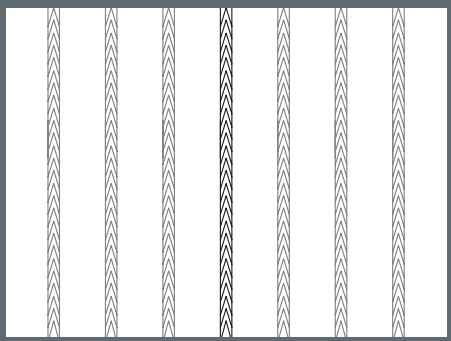

h

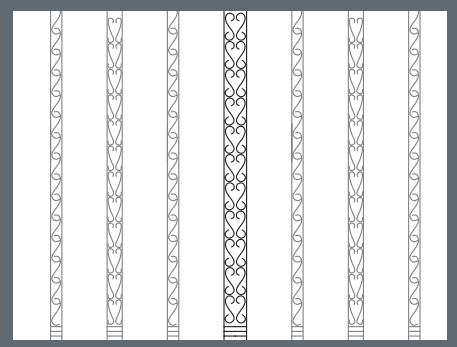

i

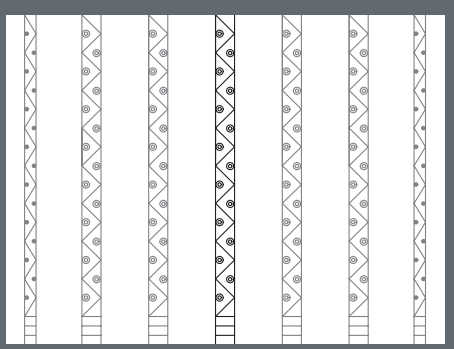

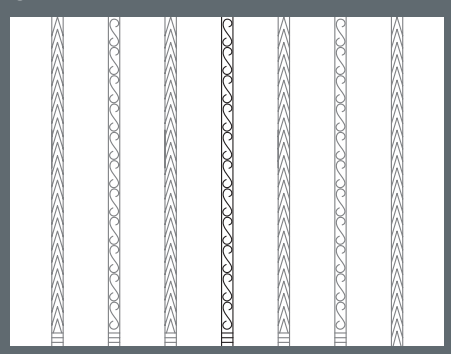

h 
4. Para ambos tipos, las densidades de tramas y urdimbres fluctúan entre valores medios y altos, habiendo una mayor preponderancia de las densidades medias: mientras que en el caso de la densidad de trama el $94 \%$ y el $63 \%$ de los ejemplares de Pampa Contrastada y Monocroma respectivamente presentan densidades medias, el 65\% del Tipo 1 y 72,7\% del Tipo 2 presentan también densidades de trama medias.

5. Las terminaciones de las orillas de urdimbre de ambos tipos presentan una preponderancia de pasadas de cable (65\% en el Tipo 1 y $75 \%$ en el Tipo 2), mientras que en las orillas de trama el hilván es la técnica más frecuente ( $76,4 \%$ y $72 \%$, respectivamente). Ahora bien, tal como mencionamos, esta técnica suele ser combinada con otras formas de terminación.

6. Las reparaciones no son usuales en ninguno de los dos tipos y han sido detectadas solo en cuatro ejemplares del tipo Pampa Contrastada.

7. En la totalidad de los ejemplares estudiados, el color de la trama se restringe a distintas tonalidades de café, siendo la policromía una característica exclusiva de las urdimbres. Los colores blanco, mostaza, crema, distintos tonos de café, rojo, amarillo ocre, y distintas tonalidades de azul y verde son utilizados por los dos tipos de chuspas. El beige es propiedad exclusiva de los ejemplares del tipo Pampa Monocroma. Café, rojo, crema y amarillo ocre son los colores más utilizados por ambos tipos. Con excepción de dos ejemplares de tipo Pampa Contrastada en los que se aprecian módulos de color rojo y café, la pampa de las demás 37 bolsas está manufacturada en base a distintas tonalidades de café, y no presentan fibras teñidas.

8. Es recurrente la coloración artificial de las fibras con las que se realizan los motivos y se manifiesta en el 76,4\% de los ejemplares de Pampa Contrastada y en el 100\% de los ejemplares de Pampa Monocroma. Los colores teñidos que se utilizan son el rojo y distintas tonalidades de verde y azul.

9. En relación con la presencia de asas, estas se restringen al 26\% de los ejemplares de Pampa Contrastada. Un $26 \%$ adicional presenta un cordel delgado destinado al cierre de la boca de las chuspas. Por el contrario, los ejemplares de Pampa Monocroma no presentan asa, y un 50\% de ellos presenta la cuerda mencionada.

10. El $76,4 \%$ de los ejemplares de Pampa Contrastada y el 50\% de los de Pampa Monocroma presentan algún tipo de contenido en su interior. Para ambos casos, los restos de material vegetal son el relleno más frecuente, alcanzando el 58\% y 41,6\%, respectivamente.

11. En cuanto a los motivos, en ambos tipos de chuspas cada franja vertical es decorada con un solo motivo geométrico de variable complejidad que se repite a lo largo de esta, hasta llenarla. 16 y 14 motivos distintos han sido detectados para el tipo Pampa Contrastada y Pampa Monocroma, respectivamente, ocho de los cuales son compartidos por ambos tipos: voluta en "S", doble voluta en "S" enfrentada, voluta en "S" concatenada, k'utu, motivo en "Z", zigzag con círculos concéntricos, chevrón y reloj de arena. A pesar de ser compartidos, algunos tienen mayor representatividad dentro de un tipo determinado: mientras que el k'utu y el jaspeado son característicos del tipo Pampa Contrastada, el chevrón aparece con mayor frecuencia en los ejemplares de Pampa Monocroma.

13. Respecto a los motivos exclusivos de cada tipo de chuspa, es importante señalar que se puede apreciar cierta familiaridad entre algunos diseños de ambos grupos. Nos referimos específicamente a hexágonos, octógonos y volutas en "S". Mientras que los hexágonos y octógonos de las bolsas chuspas tipo Pampa Contrastada se constituyen a partir de gruesos bordes y presentan dos hexágonos y dos octógonos inscritos en sus respectivos interiores, en el tipo Pampa Monocroma los mismos motivos constituyen sus lados a partir de una sola línea y por albergar en su interior un único hexágono y rombo. Si bien en ambos tipos de chuspas se presentan volutas en "S" enfrentadas por la espalda, en las chuspas con pampas Monocromas están siempre concatenadas y acompañadas de puntos.

14. De manera paralela a las semejanzas mencionadas, también se detectan en el tipo Pampa Contrastada formas geométricas que, a simple vista, no presentan familiaridad alguna con los motivos encontrados en 
el otro tipo de chuspas. Nos referimos a los motivos ondulantes, a los círculos concéntricos dispuestos en una franja vertical y al motivo jaspeado.

\section{DISCUSIÓN}

El análisis tecnológico no arroja diferencias significativas entre los tipos Pampa Contrastada y Pampa Monocroma. Sin embargo, el hecho de que la distribución espacial de las franjas que decoran la superficie de las chuspas se ciña a patrones estandarizados diametralmente distintos en cada caso y la constatación de que existen evidentes predilecciones por determinados motivos en cada grupo, nos lleva a proponer que se trata de dos estilos diferentes de bolsas chuspas.

¿Qué sucede si comparamos los ejemplares de Azapa 15, tanto del Tipo 1 como del Tipo 2 (Pampa Contrastada y Pampa Monocroma), con las bolsas chuspas de la cultura Arica, definidas por Horta y Agüero (1997)? Aun cuando es posible detectar ciertas similitudes entre ambos grupos, tales como la técnica de faz de urdimbre o la decoración simétrica consistente en franjas verticales equidistantes en cuyo interior se inscriben motivos geométricos de variable complejidad, y que en ambos casos las fibras teñidas se concentran en las urdimbres, las diferencias son evidentes: el tipo local suele presentar forma trapezoidal, la superficie se decora invariablemente con tres franjas verticales, sus motivos están manufacturados en base a urdimbres complementarias, pueden presentar flecadura y las terminaciones en las costuras laterales se restringen mayoritariamente a distintas variedades de festón, mientras que las técnicas registradas para las orillas de trama son la puntada en 8 , encandelillado, festón simple y festón doble. Junto con lo anterior, la diferencia más notoria parece ser la tradición iconográfica registrada para cada grupo.

Si bien ha quedado en evidencia que los ejemplares de chuspas de Azapa 15, a pesar de haber sido excavados en el valle de Azapa, difieren estilísticamente de las chuspas de la cultura Arica, tras describir y analizar los ejemplares del tipo Pampa Contrastada constatamos que tanto su distribución espacial como sus motivos coinciden con los establecidos para el estilo Inca. A pesar de que no contamos con el estudio tecnológico de algún corpus de chuspas de estilo Inca con el que pudiésemos comparar nuestros ejemplares, contamos con la descripción de Pollard (1995-1996) sobre bolsas chuspas incaicas: forma cuadrangular, decoración de la superficie con líneas verticales -presentando los ejemplares más complejos motivos geométricos inscritos en ellas-, terminaciones laterales sencillas y presencia de asas son algunos de los rasgos que propone como característicos y distintivos de tal estilo. Al profundizar en este asunto, menciona la presencia recurrente del zigzag, de círculos simples o concéntricos y del motivo jaspeado, y agrega que son manufacturados como bordados y/o urdimbres o tramas complementarias. Por otra parte, tras observar detenidamente los ejemplares incas de los museos British, Peabody y del Museo Nacional de Antropología, Arqueología e Historia del Perú, confirmamos que todos ellos presentan módulos de colores contrastantes y que el k’utu y el motivo jaspeado aparecen en la mayoría de las chuspas, lo que coincide con lo constatado en los ejemplares de Pampa Contrastada de nuestro corpus (fig. 12). De esta manera, las chuspas de tipo Pampa Contrastada de Azapa 15 concuerdan tanto con la escueta definición de Pollard como con la apariencia de los ejemplares que recién mencionamos, situación que parece respaldar la hipótesis del carácter exógeno del sitio en cuestión.

Los ejemplares del tipo Pampa Monocroma, por su parte, no coinciden con los estilos recién mencionados. Ahora bien, si consideramos los resultados de las diversas excavaciones e investigaciones arqueológicas realizadas en Azapa 15 que vinculan al sitio con tierras altas, así como las diversas fuentes etnohistóricas analizadas por Hidalgo (1981, 1996, 1997, 2004), Hidalgo y Focacci (1986) y Durston e Hidalgo (1997) que mencionan la presencia de colonias altiplánicas en Lluta, Arica, Azapa y Codpa, nos aventuramos a pensar en una tradición altiplánica de bolsas chuspas. Si bien es un hecho que los problemas de conservación del registro arqueológico del área han dificultado proponer una definición estilística de este tipo de textil, nuestro planteamiento se ve respaldado por uno de los trabajos de Pollard (19951996) donde la autora denomina "chuspa altiplánica" a un ejemplar que sigue los mismos patrones que nuestros monocromos: una pampa de un solo color surcada por siete franjas verticales en cuyo interior se inscriben chevrones y motivos en " $Z$ ", además de la presencia de dos cuerdas delgadas en los extremos superiores de los laterales, destinados a amarrar la boca de la bolsa (fig. 13). ${ }^{9}$ Si las observaciones planteadas hasta aquí son correctas, la presente investigación implicaría un 


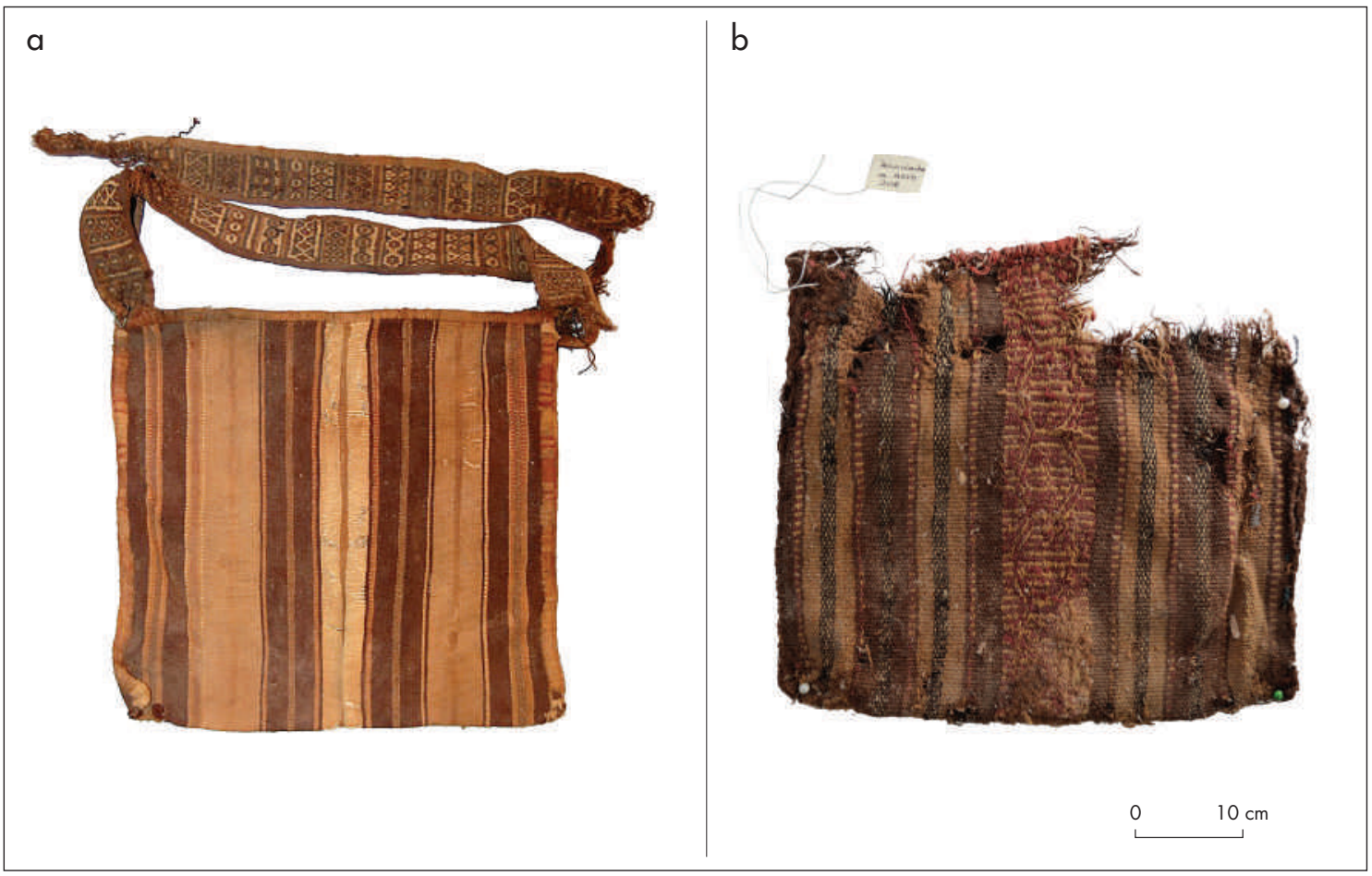

Figura 12: a) ejemplar inca; b) ejemplar de tipo contrastado asociada a Azapa 15, no 208, sin tumba. Figure 12: $\boldsymbol{a}$ ) Inca sample; $\boldsymbol{b}$ ) contrasted type sample associated with Azapa 15, $n^{\circ} 208$, without tomb.

avance en la definición del estilo textil altiplánico del Período Tardío. Adicionalmente, la hipótesis de que la población de Azapa 15 correspondería a mitimaes altiplánicos incanizados también se vería respaldada (Dauelsberg 1959; Focacci 1981; Piazza 1981; Santoro \& Muñoz 1981; Horta 2011, 2013, 2015). ${ }^{10}$

¿Cómo se explican entonces, las similitudes constatadas entre los estilos Pampa Contrastada y Pampa Monocroma? Consideramos que los elementos comunes podrían responder a la temprana incanización de la zona aymara mencionada por Llagostera (1976), o que incluso podrían ser el reflejo de un proceso de sincretismo surgido con anterioridad a la conquista del altiplano por parte de los incas, consecuencia del estrecho contacto interétnico que parece haber caracterizado a los habitantes de las tierras altas del área centro-sur andina en tiempos prehispánicos.

Más allá de estos rasgos comunes que denotarían sincretismo, nos preguntamos cómo se explica la coexistencia de dos diferentes estilos de bolsas chuspas en Azapa 15. Si los pobladores eran aymaras incanizados, ¿por qué no encontramos solo ejemplares de tipo monocromo en los ajuares? ¿qué podemos inferir de la presencia de ejemplares de Pampa Contrastada, evidentemente incaicos? Buscando dar respuesta a esta última interrogante, analizamos los contextos funerarios de Azapa 15 y detectamos tres patrones que pueden ser relevantes:

1. Salvo una excepción correspondiente a la tumba $\mathrm{N}^{\circ}$ 92, ejemplares de Pampa Contrastada y Monocroma no aparecen de manera simultánea en un mismo ajuar funerario. Ahora bien, es importante mencionar que solo 15 de los 23 ejemplares de Pampa Contrastada, y ocho de las 12 chuspas de Pampa Monocroma presentan información contextual.

2. Si bien la mayoría de los objetos depositados en los diversos ajuares de Azapa 15 son de carácter utilitario, el registro material de las tumbas que presentan chuspas de Pampa Contrastada presenta una mayor cantidad de objetos de prestigio: mientras que en ocho de las 12 tumbas hay objetos de metal -una tincurpa, tumis, láminas de metal de 


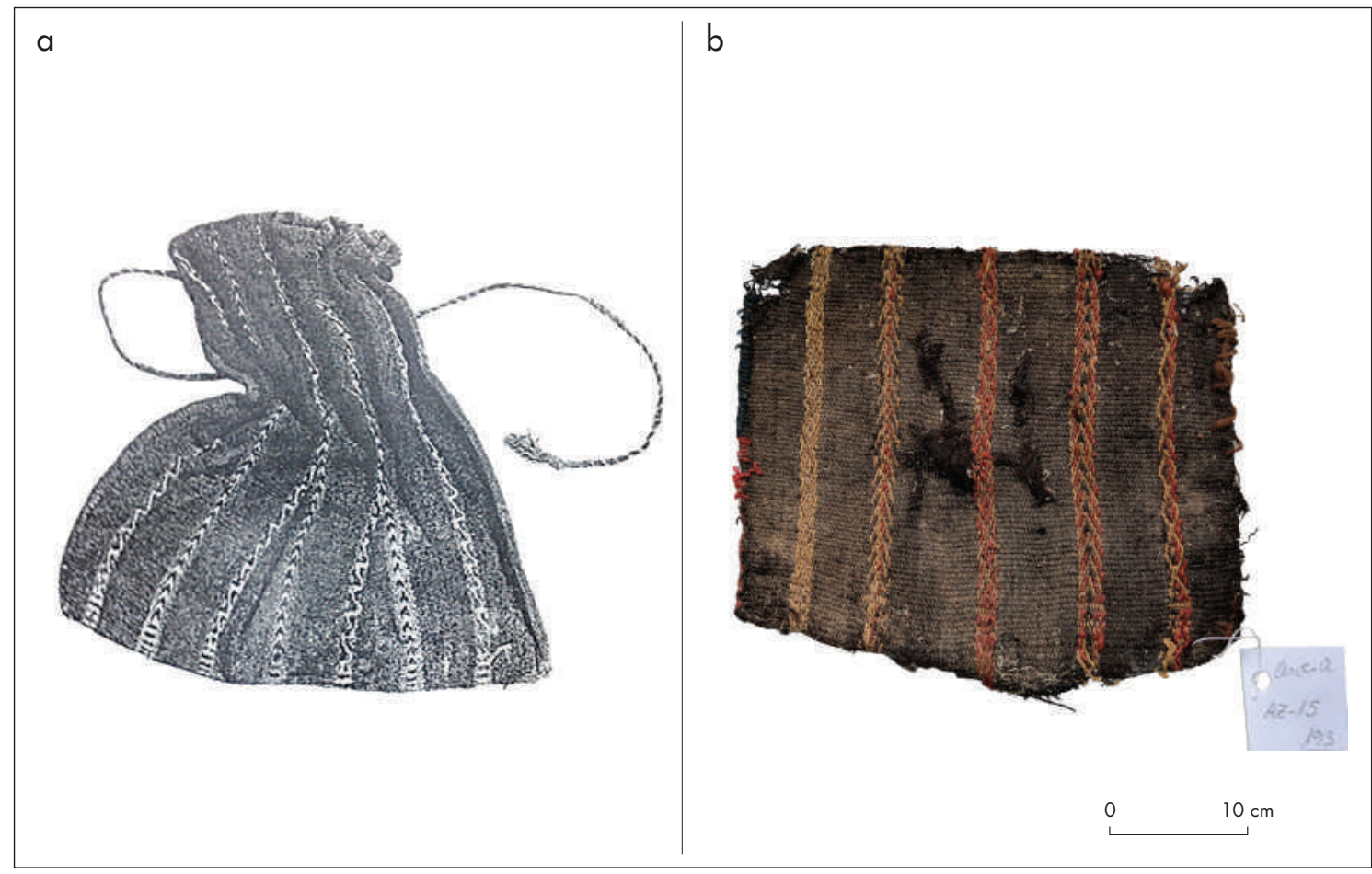

Figura 13: a) ejemplar altiplánico según Pollard (1995-1996, fig. 55); b) ejemplar monocromo asociado a Azapa 15, nº 193 sin tumba. Figure 13: a) Altiplano sample as per Pollard (1995-1996: fig. 55); b) monochromatic sample associated with Azapa 15, $n^{\circ} 193$, without tomb.

diversas formas a modo de adornos personales, agujas de cobre, tupus, un punzón, dos pendientes en forma de disco, un anzuelo y un arpón con barba metálica, entre otros- los ajuares con presencia de chuspas monocromas registran un único objeto de metal, correspondiente a una chipana asociada a la tumba ${ }^{\circ} 5$.

3. La presencia de objetos incaicos y chuspas monocromas en un mismo ajuar funerario y de objetos altiplánicos y chuspas contrastadas es poco usual. Mientras tres tumbas presentan simultáneamente chuspas contrastadas y cerámica de tierras altas (un arríbalo con aspas en la no 40 y dos escudillas Saxamar en las tumbas n 36 y 97 , respectivamente), solo en una tumba se ha identificado una chuspa de Pampa Monocroma acompañada de cerámica incaica (dos escudillas de estilo Inca Imperial en la $\mathrm{n}^{\circ} 5$ ). Cabe destacar que esta última tumba es una de las más conspicuas, ya que presenta además otros objetos de raigambre altiplánica, tales como tres gorros en técnica de aduja, dos fragmentos de faja en twill, dos catari queros y un unku listado (según Horta 2015). En función de estas constataciones e intentando explicar la presencia simultánea de los estilos Pampa Monocroma y Pampa Contrastada en Azapa 15, proponemos de manera preliminar las siguientes hipótesis:

Habría existido un estrato dirigente de origen incaico impuesto por el Estado, el cual se encargaba de la administración de los mitimaes. Este estrato habría cohabitado con una población subordinada proveniente de tierras altas y previamente incanizada. Tales dirigentes habrían traído consigo ciertos elementos de su registro material característico, entre ellos las bolsas chuspas de Pampa Contrastada. Debido a su jerarquía dentro de la población mitimae, sus ajuares funerarios habrían sido más ricos que los de los individuos de raigambre altiplánica. Desde esta perspectiva, la poco frecuente pero existente asociación en un mismo ajuar funerario de cerámicas altiplánicas y chuspas de Pampa Contrastada podría explicarse por el intercambio de productos resultante del contacto cotidiano entre los distintos integrantes del grupo mitimae. Este planteamiento encuentra respaldo en la siguiente cita de Cobo: 
Lo primero que hacían estos Reyes en ganando una provincia, era sacar délla seis o siete mil familias [...] y en trueque déllas, metían otra tanta gente [...], y entre ellos muchos orejones de la sangre real. Estos tales que se avecindaban en las nuevas tierras, eran llamados mitimaes, que es tanto como decir hombres advenedizos y extraños, á diferencia de los naturales (Cobo 1956 [1653]: 242, énfasis nuestro).

La segunda hipótesis es que las chuspas de Pampa Contrastada podrían haber llegado a Azapa 15 como parte de los obsequios que el gobernante inca solía realizar a los diversos mitimaes existentes en el Tawantinsuyu: "Y como á gente de guerra les daba [a los mitimaes] algunos privilegios con que pareciesen más nobles" (Cobo 1956 [1653]: 243). ¿En qué consistían estos "privilegios para parecer más nobles"? A pesar de que no tenemos información más precisa al respecto, sabemos que el textil era considerado por los incas como un bien de prestigio, además de ser el obsequio por antonomasia. El hecho de que los objetos de origen incaico no estén presentes en la totalidad de las tumbas, restringiéndose más bien a un selecto grupo de ellas, nos lleva a plantear que los receptores de los obsequios habrían correspondido a un estrato selecto de individuos aymaras incanizados al interior de la población trasplantada al valle de Azapa en Arica.

\section{NOTAS}

${ }^{1}$ La presente investigación corresponde en líneas generales a un capítulo de la tesis de magíster titulada "Una aproximación al problema de la multietnicidad en los valles occidentales durante el Período Tardío a partir del estudio de las bolsas chuspas de Azapa 15, Arica”, realizada en el Programa de Magíster en Antropología, mención Arqueología, de la UTA-UCN.

${ }^{2}$ Al respecto, véase Cieza de León (1996 [1553]: 34) y Cobo (1956 [1653]: 224).

${ }^{3} \mathrm{Al}$ respecto, véase Cieza de León (1996 [1553]: 64).

${ }^{4}$ En relación con este punto, es importante mencionar que diversos estudios etnográficos realizados en el área andina han revelado que la denotación de identidad continúa siendo uno de los rasgos característicos de los textiles (Blum 1986, Franquemont 1986, McKelvy et al. 1986, Meisch 1997, entre otros). A modo de ejemplo, después de realizar diversos trabajos de campo durante los años 80 en una comunidad quechua ubicada en las cercanías de Chinchero, Franquemont (1986) concluye que las mujeres reflejan su pertenencia étnica fundamentalmente a través de los pallau, variados motivos que utilizan para decorar sus llijllas. Si bien no mencionan la presencia de motivos similares a los descritos por Franquemont (1986), Blum (1986), Mc Kelvy et al. (1986) y
Meisch (1997), -entre otros- respaldan el carácter denotador de identidad de los textiles tras realizar estudios en comunidades del norte de Ecuador, Huánuco (Perú) y entre grupos Calcha (Bolivia), respectivamente. Meisch (1997), por su parte, señala que cada vez que alguien deja su comunidad y visita una ajena, se viste con la vestimenta tradicional de su lugar de origen, honrando así a sus antepasados y a su tradición.

${ }^{5}$ Proyecto titulado Etnicidad e identidad cultural: una visión desde la textilería prehispánica, dirigido por L. Ulloa.

${ }^{6} \mathrm{El} \mathrm{9,3 \%}$ restante está conformado por cuatro chuspas, de las cuales una es de estilo Arica y dos aparentemente de estilo Tarapacá. No hemos podido asociar el cuarto ejemplar a ningún estilo ya definido debido a su mal estado de conservación. Suponemos que estos tres ejemplares llegaron a Azapa 15 vía intercambio.

${ }^{7}$ Aunque uno de ellos es mitad encandelillado, mitad festón.

${ }^{8}$ Coincidentemente, dos de estas tres franjas centrales que presentan diseños distintos forman parte de las cuatro franjas centrales más anchas mencionadas anteriormente.

${ }^{9}$ El ejemplar en cuestión fue hallado a modo de ofrenda en Pachacamac, Perú, por lo que su lugar de procedencia original dentro del altiplano nos es desconocida.

${ }^{10}$ El cementerio costero de Playa Miller 6 también presenta en sus ajuares ejemplares de los tipos Polícromo y Monocromo. Ahora bien, el número de chuspas de Pampa Monocroma es reducido en comparación con las del tipo Polícromo/Incaico, y también respecto de estilo Arica presentes en el sitio. En este caso, la presencia de ejemplares monocromos se explica por el carácter tardío del cementerio y por los contactos interétnicos que caracterizaron a los valles occidentales durante el Período Tardío.

\section{REFERENCIAS}

AgüEro, C. 1998. Tradiciones textiles de Atacama y Tarapacá presentes en Quillagua durante el Período Intermedio Tardío. Boletín del Comité Nacional de Conservación Textil 3: 103-128.

AgüEro, C. 2000. Las tradiciones de tierras altas y de valles occidentales en la textilería arqueológica del valle de Azapa. Chungara 32 (2): 217-226.

BLUM, M. 1986. Costume as communication-etnographic costumes and textiles from middle America and the central Andes of South America. Bristol: Brown University.

CARmona, G. 2010. Los nuevos patrones formales y decorativos en las bolsas chuspa del área de Arica, bajo el predominio del Tawantinsuyu: una aproximación inicial. Actas del XVII Congreso Nacional de Arqueología, pp. 23-32.

Cassman, V. 2000. Prehistoric ethnicity and status based on textile evidence from Arica, Chile. Chungara 32: 253-257.

Cieza de León, P. 1996 [1553]. Crónica del Perú. Lima: Academia Nacional de la Historia. 
Clark, N. 1993. The Estuquiña textile tradition. Cultural patterning in late prehistoric fabrics, Moquegua, far southern Peru. Tesis para optar al grado de Doctor en Antropología, Washington University.

Сово, B. 1956 [1653]. Historia del Nuevo Mundo. Madrid: Biblioteca de Autores Españoles 92.

Dauelsberg, P. 1959. Contribución a la arqueología del valle de Azapa. Boletín del Museo Regional de Arica 3: 36-46.

Decoster, J. 2005. Identidad étnica y manipulación cultural: la indumentaria inca en la época colonial. Estudios Atacameños 29: 163-170.

Durston, A. \& J. Hidalgo. 1997. La presencia andina en los valles de Arica, siglos XVI-XVIII: casos de regeneración colonial de estructuras archipielágicas. Chungara 29: 249-273.

FigueroA, V. 2012. La métallurgie préhispanique des pêcheurs du littoral Pacifique dans le Chili Septentrional. París: Universidad París 1 Panthéon-Sorbonne.

FocaccI, G. 1981. Descripción de un cementerio incaico en el valle de Azapa. Chungara 7: 212-216.

Franquemont, C. 1986. Chinchero pallays. An ethnic code. En The Junius B. Bird conference on andean textiles, A. Pollard Rowe, Ed., pp. 331-338. Washington DC: The Textile Museum.

Hidalgo, J. 1981. Culturas y etnias protohistóricas: área andina meridional. Chungara 8: 209-253.

Hidalgo, J. 1996. Relaciones protohistóricas interétnicas entre las poblaciones locales y altiplánicas en Arica. En La integración surandina cinco siglos después, X. Albó, Ed., pp. 161-173. Cuzco: Centro de Estudios Regionales Bartolomé de Las Casas.

Hidalgo, J. 1997. Los yungas de Tarata en el siglo XViII. En Arqueología, antropología e historia en los Andes, R. Varón \& J. Flores, Eds., pp. 425-442. Lima: IEP.

Hidalgo, J. 2004. Historia andina en Chile. Santiago: Universitaria.

Hidalgo, J. \& G. FocaCCI. 1986. Multietnicidad en Arica, siglo XVI, evidencias etnohistóricas y arqueológicas. Chungara 16-17: 137-147.

HODDER, I. 1982. Symbols in action: ethnoarchaeological studies of material culture. Cambridge: Cambridge University Press.

HorTa, H. 2011. El gorro troncocónico o chucu y la presencia de población altiplánica en el norte de Chile durante el período Tardío (ca. 1470-1536 DC). Chungara 43: 551-580.

Horta H. 2013. Queros de madera del Collasuyo: nuevos datos arqueológicos para definir tradiciones (s. XIV-XVI). Estudios Atacameños 45: 95-116.

Horta, H. 2015. El señorío Arica y los reinos altiplánicos (10001540 DC). Complementariedad ecológica y multietnicidad durante siglos los pre-conquista en el norte de Chile. San Pedro de Atacama: Universidad Católica del Norte.

Horta, H. \& C. AgüEro. 1997. Definición de chuspa: textil de uso ritual durante el período Intermedio Tardío, en la zona arqueológica de Arica. En Actas del XIV Congreso Nacional de Arqueología Chilena, pp. 45-82. Copiapó: Museo Regional de Atacama.
Llagostera, A. 1976. Hipótesis sobre la expansión incaica en la vertiente occidental de los Andes meridionales. En Homenaje al R. P. Gustavo Le Paige S. J., J. Casassas, Ed., pp. 203-218. Antofagasta: Universidad Católica del Norte.

McKelvy, R., N. Raleigh \& E. MendizÁBAl. 1986. Textiles, weaving, and ethnic groups of highland Huanuco, Peru. En The Junius B. Bird conference on andean textiles, A. Pollard Rowe, Ed., pp. 339-349. Washington DC: The Textile Museum.

Meisch, L. 1997. Traditional textiles of the Andes: life and cloth in the highlands. The Jeffrey Appleby Collection of andean textiles. San Francisco: Thames \& Hudson.

Minkes, W. 2005. Warp the dead. The funerary textile tradition from the Osmore valley, south Peru, and its social-political implications. Tesis para optar al grado de Doctor en Arqueología, Archaeological Studies, Leiden University, Leiden.

Murra, J. 1972. El "control vertical" de un máximo de pisos ecológicos en la economía de las sociedades andinas. En Visita de la Provincia de León de Huánuco (1562), Íñigo Ortiz de Zúñiga, Visitador, J. Murra, Ed., pp. 429-476. Huánuco: Universidad Nacional Hermilio Valdizán.

MurRA, J. 1975. Formaciones económicas y políticas del mundo andino. Lima: IEP.

Murra, J. 1976. Los límites y las limitaciones del archipiélago Vertical en los Andes. En Homenaje al R. P. Gustavo Le Paige S. J., J. Casassas, Ed., pp. 141-146. Antofagasta: Universidad Católica del Norte.

OAKLand, A. 1992. Textiles and ethnicity: Tiwanaku in San Pedro de Atacama, north Chile. Latin American Antiquity 3 (4): 316-340.

Pinzza, F. 1981. Análisis descriptivo de una aldea incaica en el sector Pampa Alto Ramírez. Chungara 7: 172-216.

Pollard, A. 1995-1996. Inca weaving and costume. Textile Museum Journal 34-35: 5-53. Washington DC.

Rostworowski, M. 1988. Historia del Tahuantinsuyu. Lima: IEP.

SAntoro, C. \& I. MuÑoz. 1981. Patrón habitacional incaico en el área de Pampa Alto Ramírez. Chungara 7: 144-171.

Schiappacasse, V., V. Castro \& H. Niemeyer. 1989. Los desarrollos regionales en el Norte Grande (1000 a 1400 DC). En Culturas de Chile: prehistoria, J. Hidalgo, Ed., pp. 181-220. Santiago: Andrés Bello.

Sinclaire, C. 1998. Los gorros de cuatro puntas de la colección arqueológica Manuel Blanco Encalada: tipología y secuencia para el valle de Azapa, Arica. Boletín del Comité Nacional de Conservación Textil 3: 169-184. Santiago.

Sinclaire, C. 2001. Vestimenta, identidad y prestigio durante el Tawantinsuyu en Chile. En Tras la huella del Inka en Chile, pp. 52-59. Santiago: Museo Chileno de Arte Precolombino.

UlloA, L. 1981. Estilos decorativos y formas textiles de poblaciones agromarítimas en el extremo norte de Chile. Chungara 8: 109-136.

UlLOA, L. Dir. 1997-2000. Etnicidad e identidad cultural: una visión desde la textilería prehispánica. FONDECYT № 1970840. 